\title{
Cultura da rua ou cultura da escola? *
}

Agnès van Zan ten

CNRS, FondationNationaledesSciencesPolitiques

\section{Resumo}

Este ar ti go obje tiva es tu dar a cons tru ção de ati tu des e prá ti cas desviantes de adoles cen tes de ori gem fran ce sa ou imi gran tes. Os da dos da pes qui sa fo ram ob ti dos em uma pes qui sa de campo que in clu iu ob serva ções e en tre vis tas re a li za das ao lon go de dois anos numa escola da periferia parisiense,

A hi pó te se cen tralé a de que os ado les cen tes dos ba ir ros pe ri féri cos, ao in gres sa rem no en si no mé dio, já es tão pre dis pos tos à cul tu ra da es co la ou à cul tu ra da rua, cu jas pre dis po si ções fo ram estruturadas na família, na comunidade ou nas escolas primárias. Assim, é nos colégios, em in te ra ção com processos especificamente escolares, que se desenvolvem condutas desviantes em alguns deles.

Este texto evoca, primeiramente e de maneira geral, como os jo vens per ce bem as in ter pe la ções e di fe ren ças en tre o co lé gio e o ba ir ro, para em se gui da vol tar a aten ção para três di men sões da so ci a bi li da de ado les cen te que ex pres sam as ten sões en tre a rua e a es co la: as ami za desju ve nis, a so ci a bi li da de em sala de aula e as relaçõesinterétnicas.

A con clu são res sal ta o peso que os pro ces sos de se gre ga ção têm para a per da da ca pa ci da de in te gra tiva da es co la, quer se tratem dos pro ces sos que ocorr rem nos es ta be le ci men tos com um todo, quer sejam os que tomam lugar nas salas de aula.

\footnotetext{
Correspondênciapara:

Agnès van Zan ten

CNRS - Fondation Nationale

desSciences Politiques

11, rue de Gre nel le

75007 Pa ris - Fran ce

e-mail:

agnes.vanzanten@osc.scien-

ces.po.fr

* Trabalhoapre sentadonoGT SociologiadaEducação, du ran te a Re u nião Anu al da ANPED, 1999, Caxam bu (MG). Tra du ção de Gu iIher me João de Fre itas Teixeirae revisão técnica de Léa Pinheiro Paixão.
}

\section{Palavras-chave}

Comportamen to desviante- Adolescentes - Sociabilidade. 


\title{
Street culture or school culture?
}

Agnès van Zan ten

CNRS, FondationNationaledesSciencesPolitiques

\section{Abstract}

This article presents a study on the construction of deviant attitudes and practices on the part of French adolescents or immigrants. It is based on a fieldwork that included observations and interviews conducted along two years in a school of the Parisian periphery.

The central hypothesis is that the adolescents of the outskirts neighborhoods, as they enter secondary school, are already predisposed to the culture of the school or to the culture of the street; predispositions that were structured in the family, in the community or in the elementary schools. Therefore, it is at the secondary schools, in interaction with processes specifically related to the school, that some of them develop deviant conducts.

This text evokes, firstly and in a general way, how the youths perceive the questionings and differences between the school and the neighborhood. It then shifts its focus to three dimensions of the adolescent sociability that express the tensions between the street and the school: the juvenile friendships, the sociability in the classroom and the interethnic relationships.

The conclusion emphasizes the importance of processes of school segregation, in the school as a whole and within the classrooms, to the loss of the integrative ability of the school.

\section{Keywords}

Deviant behavior - Adolescents - Sociability.

\author{
Correspondence: \\ Agnès van Zan ten \\ CNRS - Fondation Nationale \\ desSciencesPolitiques \\ 11, rue de Gre nel le \\ 75007 Pa ris - Fran ce \\ e-mail: \\ agnes.vanzanten@osc.scien- \\ ces.po.fr
}


Será possível es ta bele cer umvín culo entre a trans gres são e a so ci a bi li da de dos ado les centes que fre qüen tam os co lé gi os ${ }^{1}$ da pe ri fe ria? A as so ci a ção es pon tâ nea des ses dois fe nô me nos é feita, ha bi tual men te, tan to pelos pais que ficam pre o cu pa dos com as más com pa nhias dos filhos, quan to pelos pro fes so res e di re to res dos es ta bele cimen tos de en sino que se queixam da atividadedos "grupinhosinfluen tes" nas tur mas e nos recintos escolares. No entanto, in fine, são as explicações atinentes a fatores psicológicos ou ex tra-escolares que, em ge ral, pre do mi nam na idéia do sen so co mum, se gun do a qual exis ti riam alunos, de um lado, "pró-escola" e, do ou tro, "antiescola", sendo que o problema essencial seria o do encontro das duas facções no es pa ço es co lar. Em com pen sa ção, a hi pó te se que se en con tra no pon to de par ti da des ta pesqui sa é a se guin te: se os ado les cen tes en tram na escola com predisposições, relativas à cultura es co lar ou à cul tu ra da rua, já es tru tu ra das parci al men te em ou tros me i os de vida, é no pró prio in te ri or dos es ta bele cimen tos de en si no que, em interação com processos propriamente escolares, se de sen vol vem em al guns alu nos de ter minadas condutas desviantes e, potencialmente, delinqüentes. Aqui, por várias razões, preferimos uti li zar o ter mo trans gres são, em vez da pa lavra violência, atualmente mais na moda. Por um lado, desejamos assim marcar a filiação de nossos trabalhos com as pesquisas norte-americanas e britâni casjá em pre en di das sobre esta questão que, de forma sucinta, evocaremos mais abaixo. Por outro, apesar de assumir, eventualmente, no discurso cotidiano conotaçõesmoralistas, é a no ção de trans gressão es co lar que, em nos sa opi nião, per mi te conceitua lizarmelhora re la ção en tre cer tas ati tu des e práticas dos adolescentes com os valores e normas escolares. Por último, parece-nos que, ape sar da pru dên cia re tó ri ca e do ri gor em pí ri co da ma i or par te das re flexões e es tu dos sus ci tados, recentemente, pela noção de violên ciaesco lar (De bar bi e ux, 1996; Char lot e Emin, 1997; Debarbieux et al., 1999), tal noção tem sido associada de forma exagerada a um registro alarmista para poder ser utilizada de maneira suficientementedesapaixonadaemum trabalhocientífico.

Há mu i to tem po que as pes qui sas re la tivas à sociabilidadedosadolescen tes em meio popular operaram uma distinção entre dois mo dos de so cia bili da de: um de les mais cen trado na escola e nos valores legítimos que im preg nam a so cie da de glo bal, en quan to o ou tro está mais ori en ta do para a rua e para os va lo res locais "desviantes" em relação aos valores da so ci e da de glo bal. Em seu tra ba lho, que se tornou clássico, sobre um bairro pobre habitado por ita li a nos nos Esta dos Uni dos, W. F. Whyte (1943) opu nha, as sim, os college boysvol ta dos para os estudos e a integração na sociedade norte-americana e os corner boys que em preendiam ativi da des lí ci tas e ilí ci tas no ba ir roe, desta maneira, se integravam à sociedade lo cal. Do mesmo modo, na Grã-Bretanha, P. Will mott (1966) dis tin guia três gru pos di ferentes no âmago da comunidade adolescente de BethnalGreen, ba ir ro ope rá rio de Lon dres: um grupo orientado para os valores das classes médias, um outro voltado para os valores da clas se ope rá ria e um gru po de "revol ta dos" (rebels). Nes ta úl ti ma pes qui sa - da mes ma for ma que em ou tros es tu dos do tipo au to bi o grá fi co ouetnográfico que têm como objeto os ado lescentes britânicos (Hoggart, 1991; Young e Will mott, 1957) -, a in fluên cia da es co la so bre os jovens bolsistas de meio popular que têm acesso ao ensino clássico é colocada em evi dência de maneira minuciosa. Com efeito, os pesquisadores mostram como a escola exigia des sa mi no ria de can di da tos ao exa me de acesso às prestigiosas grammar schools não um conformismo formal, mas uma verdadeira

1. Neste estudo, a palavra colégio refere-se aos estabelecimentos de ensino secundário e, especificamente, ao "Verlaine" na periferia parisiense, onde foi feita a observação de duas turmas, aqui chamadas de $7^{\mathrm{a} F}$ e $6^{\mathrm{a}} \mathrm{D}$, pois as classes observadas, de quarta e quinta séries, no sistema escolar francês, correspondem às nossas sexta e sétima séries do Ensino Fundamental (N.T.).

2 No original, "noyaux durs" (N.T.). 
adesão à instituição através de sua linguagem, de suas ma ne i ras de ser, de sua par ti ci pa ção nas atividades culturais e esportivas organizadas pela es co la, as sim como da es co lha dos ami gos.

Se a influência da escola na construção dasiden ti da des "pró-escola" pode pa re cer evidente, apesar de se pressupor um importante investimento dos professores e alu nos nos es tabelecimen tos freqüen ta dosporjovens oriundos do meio popular, o que po de rá ser dito a res pe i to da cons tru ção dasiden ti da des "desviantes" e próximas da "cultura da rua"? Neste aspecto, existe oposição entre duas grandes ten dên ci as: uma, subja cen te na obra de Whyte, considera que a orientação para os valores e nor mas da rua e a cons ti tu i ção de uma so ci a bi li da de no seio dos ban dos de de lin qüen tes são amplamente independentes da escola. Apesar deal gu mas di fe ren ças sign nifica tivas, é tam bém in fine a po si ção de P. Wil lis (1977) no cé le bre es tu do so bre uma dú zia dejo vens lads escolarizados em uma secondary modern school de uma ci da de ope rá ria na Ingla ter ra. Com efe i to, para Wil lis, se a es co la cons ti tui re al men te o espa ço de ex pres são de uma cul tu ra da re sis tência pelo viés da con tes ta ção ver bal e não ver bal da autoridade dos professores, da recusa do trabalho es colar, da parti ci pa ção em ativi da des pro i bi das no re cin to es co lar, tais como fu mar, consumir bebidas alcoólicas ou participar de brigas, ela intervém relativamente pouco na elaboração dessa contracultura. Por um lado, os valores que lhe servem de fundamento são extra-escolares: eles resultam do casamento criativo realizado pelos jovens entre valores que ema nam da cul tu ra ope rá ria na fá bri ca e no ba ir ro e va lo res da cul tu ra "jo vem". Por ou tro, o su por te prin ci pal que per mi te sua ela bo ra ção é “o gru po in for mal”, ou seja, a as so ci a ção es pontânea de lads nos grupos que emergem, com toda a cer te za, na es co la, mas que, atra vés dos con ta tos e das fu sões com gru pos de vi zi nhan ça, tor nam-se es pa ços de pe ne tra ção dos va lo res da clas se ope rá ria na es co la, o que conduz progressiva men te a margi na lizarolu gar do es ta belecimen to de en si no na experiên cia escolar dessesadolescentes.

A outra tendência atribui à escola um pa pel cen tral na es tru tu ra ção das prá ti cas desvi an tes. Na dé ca da de 50, A. Co hen (1955) defen dia a idéia de que é na es co la que os jo vens da classe operária são levados a enfrentar os ideais sociais legítimos - que são também os das clas ses mé di as das qua is os pro fes so res são osagen tesprivilegia dos-e, simul ta neamente, a di fi cul da de de al can çar es ses ide a is por vias le gi ti mas, o que se en con tra na ori gem da busca de so lu ções de lin qüen tes que per mi tam satis fa zê-los. No en tan to, são es tu dos bri tâni cos ulteriores que analisaram verdadeiramente o pa pel dos pro ces sos es co la res na cons tru ção de culturas “anti-escola” ou desviantes. Vários tra ba lhos mos tra ram, em particular, que as inte ra ções fre qüen tes en tre alu nos, que, des de o começo e nos ramos de escolarizaçãoou tur mas menos valorizados, com partilham predisposições pouco favoráveis aos valores e normas escolares, levavam à emergência de sub cul tu ras opo si to ras mais ou me nosvi ru lentas e a uma "polarização" entre alunos “pró-escola” e alunos “antiescola” (Hargreaves, 1967; Lacey, 1970; Ball, 1981). Outras pesquisasinfluenciadas pelas teorias da rotulagem insistiram sobretudo na construção es colar das carreiras desviantes através da imposição das normas pelos professores, do processo de designação dos alunos "desviantes”, as sim como atra vés da es tig ma ti za ção daqueles que co me te ram as in fra ções mais gra ves (Hargreaves et al., 1975). Por último, outros pes qui sa do res cha ma ram a aten ção para a necessidade de distinguir entre estratégias dos alu nos - tais como, a in tran si gên cia ou a re belião - que se opõem aos va lo res da ins ti tu i ção e po dem le var a per cur sos de lin qüen tes, e outrasestratégias - tais como, a "confraternização" ou a "colonização" - que se opõem so men te à pres são exer ci da pela ins ti tu ição esco lar e que, de for ma bas tan te am pla, cons tituem de fato uma for ma de adap ta ção a esta 
(Woods, 1976; Hammersley e Turner, 1980; Peignard et al., 1998).

A análise das subculturas opositoras ou desviantes no espaço escolar foi empreendida, igual men te, com o obje tivo de com preen der melhor a re la ção es ta be le ci da, na es co la, en trejovens que fazem parte de diferentes minorias raciais e étnicas. Várias pesquisas, incluindo o estudo pioneiro de J. Ogbu (1974), chegam à mes ma con clu são, a sa ber: a opo si ção en tre esses jo vens é di fe ren te da opo si ção en tre alu nos da ma i o ria do mi nan te pelo fato de que a opo sição às nor mas da ins ti tu i ção é a com pa nha da por um nível elevado de aspirações escolares e por uma recusa menos acentuada das aprendizagens. Contudo, essas pesquisas divergem, de novo, em re la ção ao peso que atri bu em às in te rações escolares na formação dessas subculturas. Para alguns, a iden tida de so cial dosjovens das minorias constrói-se em ligação com uma experiência comunitária discriminatória e com uma "cul tu ra da rua" que for ne ce um con tra modelo de sucesso, permite a aprendizagem dos comportamen tos desvian tese forneceoportunida des de aces so a me i os ile gí ti mos (Bra ke, 1985; Ogbu, 1989; Mcle od, 1987). Para ou tros, a es cola desempenha um papel central, principalmen te pelo viés das re pri men das e san ções que transformam as brincadeiras e a desordem em rejeição aos professores e à instituição escolar (Wright, 1987; Con nolly, 1995).

No en tan to, as ati tu des e as prá ti cas - escolares ou desviantes - dos jovens que fazem parte de minorias étnicas têm sido analisadas tam bém em re la ção à so ci a bi li da de in tra-étnica e interétnica nos estabelecimentos de ensino. Váriosestudos mos tra ram as pres sões exer ci das pe los co le gas do mes mo gru po so bre os jo vens das minorias quando, nas permutascotidianas, estes tentam transpor as fronteiras étnicas ou raciais e adotar as atitudes e comportamentos dos colegas brancos que, aliás, são tam bém as ma ne i ras de ser a prova das pela ins ti tu i ção es colar (Scherer e Slawski, 1979; Fordham e Ogbu, 1986; Foley, 1990). Outros estudos mostraram que se, as políticas de dessegregação escolar não che ga ram a uma sen sível melhoria do nível de sucesso dos alunos negros, tem sido, em par te, por ca u sa de cer tas condições da in te ração in te rét ni ca nos es ta be le ci men tos de en sino. Com efeito, o reagrupamento de alunos brancos e negros, ou de adoles cen tes que fazem parte de diversas minorias, acabou colocan do na mes ma tur ma alu nos com bom nível de aproveitamento e alunos médios, de um lado e, do ou tro, mé di os ou fra cos. Ora, ape sar de cer tos es tu dos mos tra rem que a au sên cia de segregação e, sobretudo, o fato de juntar na mesma turma uma proporção equivalente de alu nos bran cos e de alu nos que fa zem par te de minorias desempenham um importante papel na fre qüên cia das in te ra ções (Hal li nan eSmith, 1985), ou tros tra ba lhos co lo cam em evi dên cia o se guin te: para tor nar be né fi cas as in te ra ções no pla no es co lar para os alu nos ne gros, im porta cri ar con tex tos de es co la ri za ção nos qua is os alu nos te nham es ta tu to es co larigual, ou as diferenças de nível escolar sejam minimizadas pela au sên cia de ava li a ção pú bli ca das com petências ou pela individualização do trabalho (Metz, 1983). No caso con trá rio, além da ten dên cia a ado tar ati tu des de re tra i men to ou revol ta na tur ma, os alu nos das mino rias ra cia ise ét ni cas pro cu ram o su ces so pelo viés de ou tros programas escolares, principalmente, as com pe ti ções es por tivas, ou en tão, por meio de atividades lícitas ou ilícitas fora dos estabelecimentos de ensino (Collins, 1979; Hallinan e Williams, 1989; Payet e Zanten, 1996).

\section{O bairro e a escola: interpenetração, separação e força de atração}

Até ago ra, na Fran ça, a ques tão das re la ções man ti das pe los ado les cen tes com a es co la ou com o ba ir ro tem sus ci ta do re fle xões que se re fe rem tan to a afir ma ções de prin cí pio, quanto à aná li se de re sul ta dos em pí ri cos. Aliás, em 
geral, a extra territoriali da de da escolaéconsidera da um va lor in con tes tá vel que pode ser apreciado sob um duplo prisma: ou é motivo de regozijo pelo fato de que a instituição escolar ainda possa servir de baluarte estatal aos "co mu ni ta ris tas" ou "se ces si o nis tas", ou, pelo contrá rio, é alvo de la men ta ções pela cir cuns tân cia de que certos estabelecimentos escolares tenham sido "invadidos" ou se tenham tornado “es pon jas" do meio cir cun dan te (Bal li on, 1997). Ora, até mesmo a análise sumária da realidade cotidiana dos estabelecimentos de ensino da periferia permite facilmente mostrar que, na prá tica, éine vi tá vel um cer to grau de in ter pe netração en tre a ex pe riên cia dos ado les cen tes no ba ir ro e o que eles vi vem no co lé gio, mes mo se a extensão e as formas de tal interpenetração variem em fun ção dos con tex tos só cio-ge o grá ficos, das políticas da instituição escolar e das práticas dos profissionais daeducação.

No caso que nos interessa aqui, existe manifestamente uma certa continuidade sócio-urbana en tre o ba ir ro e o co lé gio. ${ }^{3}$ Por um lado, o se tor de re cru ta men to da es co la corresponde,globalmente, a uma unidadeurbana: a vas ta re gião Les te da ci da de de M. que com preende vários conjuntos habitacionais ${ }^{4}$ e alguns loteamentos de casas, ocupados pela classe média. Além disso, no próprio âmago desse todo, por ra zões que têm a ver com a con cen tração de famílias numerosas nos conjuntos habitaciona is, com o envelhe cimen to da po pula ção que re si de nes sas ca sas e tam bém - como chegamos a mostrar alhures (Broccolichi e Zanten, 1997) - com a evi ta ção do co lé gio pe las fa míli as com me lhor nível so ci al e mais possi bi li da des do que as ou tras de mo rar em ca sas, o colégio acaba sendo freqüentado por uma maioria de alunos oriundos desses conjuntos habitacionais. Por tan to, uma gran de par te dos ado les cen tes que che gam à $5^{\text {a }}$ sé rie são "ado lescen tes de tais conjun tos" que com par tilham, se não uma cul tu ra co mum, pelo me nos cer tos ti pos de con du ta as so ci a dos à vida nos gran des conjun tos. A ob serva ção dos alu nos no pá tio de recreio e dos que se be ne fi ci am do re gi me de semi-internato mostra bem a presença no colégio de numerosos elementos da "cultura da rua” (Lepoutre, 1997). Unicamente pela aparência física (penteado, roupas, sapatos, aces só ri os), al guns a do lescen tes, de am bos os sexos, ma ni fes tam sua ins cri ção em tra dições comunitárias, em movimentos "étnicos", em mo das da qui e de alhu res, de fa sa dos em re lação à ima gem es te re o ti pa da do alu no ide al. É possível ouvira ma i or par te dos ado les cen tes utilizarem termos de verlan ${ }^{5}$, escarnecerem uns dos outros, insultarem-se ou xingarem-se. Ou vem-se con ver sa ções que gi ram em torno de ativi da des es por tivas, mo tos, te levisão, atu a li da de da vida política.É pos sívelver os me ni nos an da rem de um lado para o ou tro ou praticarem diversas modalidades esportivas (tê nis de mesa, fu te bol, saké), ocu pan do o re du zi do es pa ço co mum do pá tio de re creio, enquanto a maioria das meninas discute em peque nos gru pos pelos can tos. Há quem fique um pou co in qui e to com os em pur rões, as rasteiras, as bo fe ta das, os co me ços de bri ga ou ain da com os $\operatorname{tags}^{7}$ nos mu ros ou nas me sas, ou com bo a tos derou bos, trá fico, re preen sões en tre alu nos e o racket. $^{8}$

3. Aqui, baseamo-nos, essencialmente, no estudo monográfico de um colégio da periferia sul de Paris empreendido entre 1995 e 1998, graças à colaboração de Emmanuel Peignard que realizou as entrevistas e uma grande parte das observações. Este trabalho inscreve-se no quadro de uma pesquisa mais ampla que incide sobre 0 papel da escola na manutenção do vínculo social na periferia (Zanten, 2001).

4. No original, "cités" (N.T.).

5. Inversão de l'envers que significa "às avessas". Trata-se de gíria codificada em que as sílabas das palavras são invertidas - por exemplo, zarbi por bizarre (Le Petit Larousse , 1999) (N.T.).

6. Mais praticado no estabelecimento na hora do recreio e pelos beneficiários do regime de semi-internato, este jogo assemelha-se ao squash ou à pelota basca: três a cinco jogadores colocam-se diante de uma parede e lançam com a palma da mão a bola de tênis que os outros deverão apanhar e, por sua vez, lançar contra a parede. Na hora do recreio, em média, seis grupos disputam tal jogo.

7. Pichação caracterizada por um grafismo próximo da escrita e que constitui um sinal de reconhecimento ( LePetitLarousse , 1999) (N.T.).

8. Extorsão de dinheiro ou de objetos por intimidação e violência ( Le Petit Larousse , 1999) (N.T.). 
No entanto, se a sociabilidade dos ado lescentes no colégio aparece, assim, como o prolongamento da sociabilidade no bairro, os alu nos são de fato sen síve is a cer tas es pe ci fi cida des do es pa ço es colar. Uma pri me i ra es pe cificidade deve-se ao fato de que o colégio contrariamenteà família, a o ba ir ro e, em grau me nos eleva do, à es cola primá ria-, é perce bi do como um uni ver so que se re fe re me nos a uma ló gi ca co mu ni tá ria do que a uma ló gi ca de associação. Se isso acon te ce des sa for ma é porque, por um lado, no colégio, os adolescentes que mo ram na pe ri fe ria são le va dos a en fren tar numerososprofissionais da edu ca ção (cuja di versidade não cessa de au men tar ao sa bor das políticas de discriminação positiva nas zonas de educação prioritárias e nos estabelecimentos mais pro ble má ti cos) que, além de se rem na sua ma i or par te es tra nhos a o ba ir ro, es tão en raizados precariamente no estabelecimentode en si no (Hen ri ot-Zanten, 1990). Por ou tro lado, apesar de sua inserção local, o colégio reúne ado les cen tes que ain da não se co nhe ci am, oriundos de diferentes escolas e de diferentes conjun tos ha bi ta ci o na is. Ora, em ra zão de seu confinamentoespacial, os adolescentesoriundos desses conjuntos atribuem grande importân cia à re la ção fa ce-a-face, à pro xi mi da de eà con ti nu i da de no tem po em vis ta da cons tru ção das relações (Lepoutre, 1997; Bordet, 1998). Tal situação permite compreender o discurso pa ra do xal - so men te na apa rên cia - de al guns alu nos da tur ma de $7^{\text {a }}$ sé rie, es tu da da pornós: apesar da má reputação do bairro, eles declaram sentir mais segurança neste do que no colégio, opondoin terconhecimento, familiarida de e aju da mú tua de um lado, ao ano ni ma to, estranhamento e imprevisibilidade do outro lado.

- Onde é que você acha que os alu nos têm mais se gu ran ça: no co lé gio ou fora?

- Bem, você, você tem mais se gu ran ça na rua.

$-\ldots ?$
- Porque, no colégio, você não sabe o que pode acontecer. Na rua, você conhece tudo; portanto... Como você conhece todo mundo, você pode... você tem sempre a possibilidade de re cor rer às pes so as .

- Você pensa que, se hou ves se mais adul tos no co lé gio, você te ria mais se gu ran ça?

- Não, não se tra ta dis so, mas por que a gen te não os co nhe ce. Não é por se rem vi gi lan tes; a gen te os co nhe ce so men te há um ano, é isso. Qu an to às pes so as da rua, co nhe ço-as há mu ito tempo. Qu an do exis te um pro ble ma, você pode re cor rer a elas.

(Benja min, 7 $\left.^{\mathrm{F}} \mathrm{F}\right)$

- Onde é que você acha que exis te mais se gu ran ça: no co lé gio ou fora?

- Fora. Por que fora co nhe ço ami gos ou prédios com códigos, você conhece os códigos, você pode entrar, você pode esconder-se, e nin guém vai sa ber, você vai para a casa de um ami go, é só en trar.

-...? E aqui, no co lé gio, a gen te tem me nos segu ran ça do que lá fora?

- Com cer te za... Por que se, eles po dem..., por exemplo, se, eu não sei; exis tem la drões que en tram, são vá ri os... eles nada po de rão fa zer,é isso. Por exemplo, eles entram... às onze e meia, no mo men to em que não há re cre io, ninguém conseguirá vê-los. Eles sobem para a sala de aula, abrem uma sala... e podem fazê-los re féns, é isso.

(Ahmed, $7^{\text {a }} \mathrm{F}$ )

No entanto, a maior parte dos alunos con si de ra que - pelo me nos, por duas ra zões - o colégiooferece mais segurança do que o meio cir cun dan te fora do es ta be le cimen to. A primeira éque a ins ti tu i ção es co larse pa ra fa ixas etá ri as que se en con tram mis tu ra das e entram em conflito no bairro: os "irmãos mais no vos” es tão na es co la pri má ria e no co lé gio, enquanto os "irmãos mais velhos", que ten tam dominar os mais novosno ba irro, es tão, 
durante o tempo escolar, no liceu, no $\mathrm{LP}^{9}$ ou fora do sis te ma de en $\sin ^{10}{ }^{10}$ (Du ret, 1996). A se gunda razão que explica esse sentimento de maior segurança remete à segunda especificida de re co nhe ci da ao co lé gio pe los alu nos, a saber: a de fi ni ção es tri ta das nor mas e o ri gor na apli ca ção das san ções opõem-se não só à ma i or im pre ci são que ro de ia os li mi tes en tre os com porta men tos acei tos e os com por ta men tos desviantes na rua, até mesmo em certas famílias, mas tam bém à vi gi lân cia mais ir re gu lar e ar bi trá ria exer ci da, no ba ir ro, pelos mo ra do res, traba lha do res da área so ci al ou po lí cia em re la ção às condutas dos jovens. Todavia, convém observar des dejá que o res pe i to, in clu sive, a aprovação das nor mas es co la res pa re ce de pen derpelo menos, para uma parcela dos alunos muito mais de uma es tra té gia de adap ta ção às restrições do meio circundanteescolar do que de uma verdadeira interiorização dos valores que a ins ti tu ição pro cu ra pro mover, como é observado de forma minuciosa por esta aluna:

- Será que, em ge ral, você acha que os alu nos têmsuficientesegurança no colégio?

- Isso depende.

- ...? Exis tem mo men tos em que você pen sa que não há su ficien te se gu ran ça?

- Com cer te za, isso pode acon te cer; mas que ro di zer, no co lé gio, tam bém eles não sa bem o que se pas sa fora.

- ...? Fora, há... a gen te tem me nos se gu ran ça?

- Mas com certeza.

- ...? Por que motivo?

- Eu não sei. Uma briga [inaudível]. Se forem in te li gen tes, eles não vão bri gar no co lé gio...

(Christelle, $7^{\text {a }} \mathrm{F}$ )

No en tan to, será que exis tem ní ti das dife ren ças en tre gru pos de alu nos quan do se tra ta de sua postura em relação à escola e ao ba ir ro? Eis o que não é evi den te ao se rem com pa ra das as ob serva ções dos alu nos re la ti vas ao bairro. Globalmente, a maior parte dos alunos per ce be o uni ver so dos gran des con jun tos - e, em particular, o conjunto habitacional "Zola", o mais "barra pesada" - como um meio circundante, na melhor das hipóteses, “agi ta do", e, na pior, ex tre ma men tevi o len to: a pe que na de lin qüên cia, os tu mul tos, as bri gas, as sim como os car ros in cen di a dos, o trá fi co de dro gas, a ven da de ar mas, até mes mo os suicídios e os assassinatos são mencionados por qua se to dos. No en tan to, exis tem dife ren ças de tom. Estas de vem-se, em par te, à diferença nas representações da violência, segundo os sexos: as meninas manifestam maior número de rece i os do que os me ni nos (Carra e Sicot, 1997). Parece que tais representaçõescorrespondem, igualmente, a diferen ças de ida de: pelas res pos tas da das, a vi são do ba ir ro ma ni fes ta da pe los alu nos da tur ma de $6^{a}$ sé rie é mais ne ga ti va do que a dos alu nos da turma de $7^{\text {a }}$ série. Também pode ser observada uma certa correlação com a posição escolar do aluno: somente três garotas com severo fracasso escolar evocam uma visão re la tiva men te po si tiva do ba ir ro. No entanto, o elemento mais determinante continua sendo a relação de proximidade ou de afastamento físico, assim como social, em relação ao bairro. De forma evidente, existe uma opo si ção en tre o dis cur so de pre fe rên cia im pre ci so e alar mis ta dos alu nos que não re sidem no conjunto habitacional, e o discurso informado do interior que, sem legitimar a violência, apresenta-a como um fenômeno até cer to grau "na tu ral" nes te tipo de con texto. Des te pon to de vis ta, po de-se di zer que os julgamentos emitidos em relação ao bairro

9. Sigla de Lycée professionnel, estabelecimento profissional de ensino médio (N.T.).

10. A prática maciça da repetência nos colégios da periferia após a eliminação da orientação educacional no término da $6^{a}$ série, direcionada para 0 ensino técnico curto, aumentou as diferenças de idade entre alunos; no entanto, tal prática passa atualmente por um acentuado decréscimo devido a injunções oficiais em favor da homogeneização dos currículos escolares e, ao mesmo tempo, devido à tomada de consciência dos diretores de estabelecimento e dos professores em relação aos efeitos negativos dessa prática sobre 0 clima das classes e do estabelecimento. 
são mu i to mais de pen den tes da experiên cia urbana do que da experiência escolar.

Paralelamente, observa-se que os julgamen tos pro fe ri dos em re la ção à es co la pa re cem ser ori en ta dos pela po si ção es co lar. É re du zi do o nú me ro de críti cas di ri gi das pela ma i or par te dos alu nos a o co lé gio; além dis so, eles ace i tam com cer ta re sig na ção o cli ma "agi ta do" aí re inan te. De fato, são pou cos os que ex pres sam o de sejo de tro car de es ta be le ci men to de en si no, mas são igualmente escassas as observações positivas em relação ao seu funcionamento, para além do pra zer ex pe ri men ta do em en contrar aí ami gos e co le gas. No en tan to, é bas tan te ní ti do o vín cu lo com a po si ção es co lar da dú zia de alu nos (en tre os 36 que fo ram in ter ro ga dos pornós) que emi tem jul ga men tos fran ca men te nega tivos. Com efe ito, alu nos de nível bas tan te bom estimam que o colégio "Verlaine" não é uma boa escola e, particularmente, em razão dos pro ble mas de dis ci pli na; além dis so, ma nifestam o desejo de mudarpara um es tabele cimento melhor:

- 0 que você pen sa do co lé gio "Ver la i ne" como estabelecimentodeensino?

- Por alto?... einh... Trata-se de uma escola... que ten ta dis ci pli nar os alu nos; mas, no que se re fe reà dis ci pli na, es tes nem li gam.

- ...? E você pre fe ri ria es tar em ou tro es ta be lecimento?

- Sim. Eu pre fe ri ria es tar no "Paul Va léry".

- Por que mo ti vo você pen sa nes se co lé gio?

- Por que aí o nú me ro de alu nos dis ci pli na dos é

ma i or do que o nú me ro de não dis ci pli na dos.

(Na bil, 7ªF)

Entre es ses alu nos, en con tram-se, excepcionalmente, adolescentes que, para evitar a iden tifica ção com um colégio “in dis ciplina do", pro cu ram evi tar qual quer re fe rên cia ao es ta belecimen to, em bene fício do universo da turma.

- E, em ge ral, será que, para você, “Ver la i ne” é um bom co lé gio?
- ... Sim, é ace i tá vel. Con tan to que não haja bagunceiros na sala de aula, mesmo se... se exis te tu mul to fora, isso não é nada. A ques tão é na sala de aula. Se não houvertu mul to aí, tudo bem, trata-se de um bom colégio... einh... Para mim, não me interessa o que se pas sa fora, no pá tio de re cre io, es tou fa lan do da sala de aula. Isso é tudo... einh...

(Dja mel, 7 ${ }^{\mathrm{a}}$ )

Mas en con tra mos, igual men te, en tre os críticos, alguns alunos com fracasso escolar ou mé di os, mas “ba gun ce i ros", que pre fe rem descrever o colégio como uma pri são ou um deserto em relação ao clima que reina no bairro:

- 0 que você pen sa a res pe i to do co lé gio "Ver-

laine"?

-0 co lé gio é $K 0$.

$-\mathrm{KO}$ ?

- Sim, é dead.

- É o quê?

- Ele está mor to.

- É dead? Tudo bem, en ten di. 0 que não agra da a você no colégio "Verlaine"?

- Oh! o cli ma... é nulo. So men te os cur sos são bons. Qu an do você está na sala de aula, é uma beleza. Mas, por exemplo, a can tina, o sistema... está mor to o sis te ma de les.

(Tolo, $\left.7^{\mathrm{a}} \mathrm{F}\right)$

Em com pen sa ção, en tre os ra ros alu nos que têm opi niões po si tivas a res pe i to do es ta belecimentoencontramos, sobretudo, alunos de nível médio, relativamente calmos e que mantêm excelentes relações com os professores.

\section{Cada qual com seu igual? Redes de amizade na turma, no colégio e no bairro}

Outra maneira de explorar a existência ou não de uma clivagem entre alunos mais 
vol ta dos para a es co la ou para o ba ir ro con sis te em es tu dar a com po si ção de suas re des de ami gos. Com efe i to, uma vez que, nes ta fa ixa etá ria, a amizade começa a tornar-se uma importante di men são da cons tru ção da au to no mia e da expressão das escolhas pessoais, a "localização" dos amigos deveria fornecer indicações pertinen tes so bre a ori en ta ção dos alu nos. No en tanto, nem sem pre é fá cil dis tin guir en tre ami gos de es co la e ami gos de ba ir ro, de tal modo es tão imbricados esses dois universos da sociabilidade dos adolescentes da periferia. Por um lado, os ami gos de ba ir ro são, mu i tas ve zes, an ti gos amigos da escola primária, até mesmo do colégio, que não che ga ram a en trar no co lé gio "Verla ine" ou já o aban do na ram, em ra zão do aca so do zo neamen to escolar, dasorien ta ções educa cio na is ou ex clu sões. Por ou tro lado, mas isso já faz parte dos elementos a seremanalisados, a escolha dos ami gos en tre co le gas está as so ci a da di re tamente ao local de residência. Tal fenômeno é, particularmente, verdadeiro entre os jovens da periferia para quem a amizade, assim como o amor, além de se reves tir em nu me ro sos ca sos de um ca rá ter mu i to me nos ín ti mo do que a acepção usual que é atribuída a esses termos (Lagran ge, 1999), vai de par com o fato de es ta rem acos tu ma dos a pe ram bu lar pela rua, além de se de dica rema diferen tesativi da deslíci tas ou ilícitas ao mes mo tem po, o que im pli ca pro xi mi dade. Aliás, alguns alunos declaram não ter amigos; neste caso, para se divertirem, dirigem-se à pri me i ra pes soa que pas sar pela rua.

- E, no ba ir ro, você tem pre fe rên cia por al guns amigos?

- ... A bem di zer, não; não se tra ta de uma pre fe rên cia em re la ção a ou tros, é aque le... se está na rua e assim... e que eu já o conheço, neste caso, vou di zer pra ele "ve nha à mi nha casa", a gen te vai as sis tir a um ví deo ou algo pa re ci do.

(Dja mel, 7ªF)

Para a maior parte dos outros, é tal o peso da proxi mi da de que eles de cla ram que um amigodeixaria de sê-lo se viesse a mudar de residência, inclusive, na mesma cidade, até mesmo de um conjunto habitacional para outro.

- Então, o que é para você um amigo? Um bom ami go mais do que um co le ga?

- Para co me çar, é al guém que vejo fre qüen temen te, com quem vou ao ci ne ma, ou co i sa pare ci da. Mas exis tem tam bém ami gos da es co la por que há ami gos que mo ram em ou tros conjuntos habitacionais que não posso ver com tan ta fre qüên cia. Mas es ses não são ver da de ira men te ami gos; são ami gos, mas... não como aque les com quem saio e... é as sim que es tou acos tu ma do a en con trar.

(Meh di, 7aF)

- E o que é mais im por tan te para você? Será o fato de mo rar ao lado de ou tra pes soa que faz com que você se tor ne seu ami go ou você po de ria ter um ami go que mo ras se lon ge?

- Per to. Por que, por exem plo, se a gen te tem um pro ble ma, é isso, po de-se ir ao en con tro da pes soa; nes te caso, seu ami go, ele pode aju dar, ele pode fa lar com os pais, é isso.

- ...? E você pen sa que uma pes soa mo rar perto da outra é mais importante do que outra coisa quan do a gen te ga nha um ami go? Será que é isso que faz com que a gen te ga nhe um amigo e não somente um conhecido?

- Sim, é isso mesmo.

- E um ami go que mo ras se lon ge, va mos su por que você muda de casa, será que você vai fi car em con ta to com seus ami gos atu a is ou será que você pen sa que ga nha rá ou tros ami gos?

- Nes se caso, bom... ano ta rei os nú me ros de te le fo ne de les e li ga rei de vez em quan do.

- ...? E você pen sa que se mu dar para ou tra cida de, você ga nha rá ou tros ami gos que se ri am tão bons quan to seus ami gos atu a is? - Sim, sem pre... einh... por que se não de po is, você não tem ami gos, é isso... você fica so zi nho no local onde mora.

(Ahmed, 7 ${ }^{\mathrm{a} F}$ ) 
No entanto, a análise da "localização" dos ami gos dos alu nos das duas tur mas ob servadas mostra a existência de um vínculo bas tante nítido entre essa variável e a posição es co lar dos alu nos. Na tur ma de $6^{\text {a }}$ sé rie, ob serva-se que, ape sar de to dos afir ma rem ter amigos na classe, são os alunos médios e, sobretudo, os fracos, que declaram ter mais ami gos den tro e fora do co lé gio do que na sala de aula quando, afinal, o oposto é verdadeiro em re la ção aos alu nos com bom ní vel de apro ve i ta men to. Essa re la ção en tre po si ção es co lar e tipo de sociabilidade amigável ainda é mais evi den te na tur ma de $7^{\text {a }}$ sé rie, na qual os alu nos distinguiram, com maior precisão, entre os amigos da escola e os amigos do bairro. Com efe i to, como mos tra a Ta be la l, to dos os alu nos com bom nível de desempenho têm seus me-

TABELA I. Lo calização dos Me lho res Amigos Tur ma de $7^{\text {a }}$ sé rie

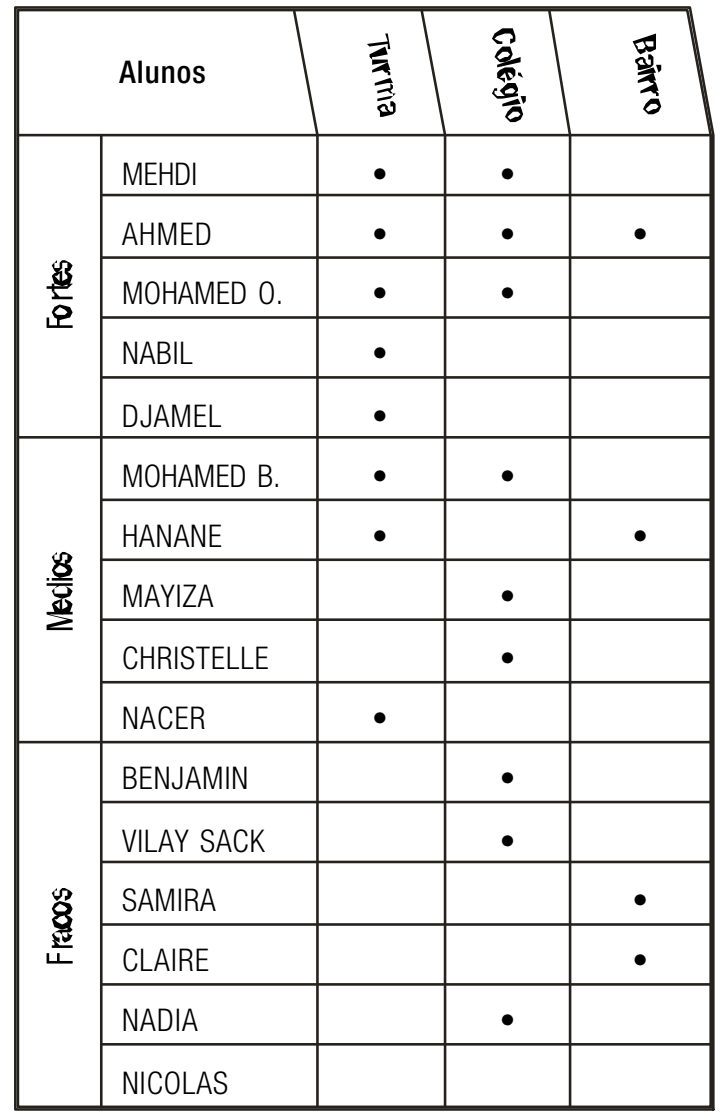

lho res ami gos na tur ma e, porve zes, no co lé gio ou no bairro; os fracos têm sobretudo amigos no bairro e, às vezes, na turma e no co lé gio; e o pior de to dos, que, aliás, de i xou o estabelecimento antes do final do ano escolar, não tinha ne nhum amigo.

To davia,éin te ressan te rela ci o narasesco lhas de ami gos dos alu nos com ou tra va riá vel es co lar, a sa ber: o com por ta men to na sala de aula, tal como pu de mos ob servá-lo no de correr de um ano es co lar e tal como ele é ava liado pelo conselho de turma nos boletins,

TABELA II. Ami gos Se gun do o Aprove itamen to Esco lar Tur ma de 6 a Sé rie

\begin{tabular}{|c|c|c|c|c|}
\hline \multicolumn{2}{|c|}{ Alunos } & \multirow{2}{*}{$\frac{\hat{\bar{a}}}{\bullet}$} & \multirow{2}{*}{$\frac{8}{\frac{8}{6}}$} & \multirow{2}{*}{ 㗊 } \\
\hline \multirow{4}{*}{ 홍 } & NELSON & & & \\
\hline & KARIM & $\bullet$ & $\bullet \bullet$ & • \\
\hline & AHMED & & $\bullet$ & \\
\hline & ASSIA & & $\bullet \bullet$ & \\
\hline \multirow{9}{*}{ 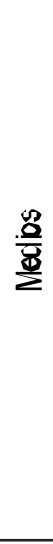 } & ALAIN & $\bullet \bullet$ & $\bullet \bullet$ & $\bullet$ \\
\hline & ALINE & - & & \\
\hline & KHALED & $\bullet \bullet$ & & $\bullet$ \\
\hline & MICKAEL & & $\bullet \bullet$ & \\
\hline & NAMA & $\bullet \bullet \bullet$ & $\bullet \bullet$ & • \\
\hline & MOHAMED & $\bullet$ & $\bullet \bullet \bullet \bullet$ & $\bullet \bullet$ \\
\hline & KEVIN & & $\bullet \bullet \bullet \bullet$ & $\bullet$ \\
\hline & ALEXANDRA & $\bullet$ & $\bullet$ & \\
\hline & NACER & $\bullet \bullet \bullet$ & $\bullet \bullet$ & \\
\hline \multirow{7}{*}{ 兽 } & IMEN & $\bullet$ & $\bullet \bullet$ & $\bullet \bullet$ \\
\hline & CELINE & & $\bullet$ & $\bullet \bullet$ \\
\hline & AZDIN & $\bullet \bullet$ & $\bullet \bullet$ & $\bullet \bullet$ \\
\hline & SONIA & & $\bullet$ & $\bullet \bullet$ \\
\hline & ANGELIQUE & & & $\bullet \bullet \bullet$ \\
\hline & LINDA & & & $\bullet \bullet$ \\
\hline & FRANCK & $\bullet$ & $\bullet \bullet \bullet$ & $\bullet \bullet \bullet$ \\
\hline
\end{tabular}


porque nem sempre existe correlação entre o desempenho nos estudos e o comportamento. Observa-se, en tão, que não exis te re la ção for te entre o comportamento de "bagunceiro" na sala de aula e a fa ci li da de em fa zer ami gos, seja na tur ma ou no ba ir ro. Tal ve ri fi ca ção re duz um tanto o alcance do resultado anterior que diz res pe i to à po si ção es co lar. Pa re ce que os "desvian tes" es co la res não es tão mais vol ta dos para o ba ir ro do que os ou tros alu nos, o que su ge re que essa trans gres são, no caso de se ali men tar da ex pe riên cia de vida no ba ir ro, não se apóia necessariamente, de forma exclusiva, em gru pos existentes fora do estabelecimento de ensino.

Mas tudo de pen de tam bém das ca rac terís ti cas es co la res dos ami gos. Ha ve rá uma ho mologia de posição escolar nas afinidades ele ti vas dos alu nos na tur ma? É o que su ge re a Ta be la ll ela bo ra da a par tir das es co lhas de clara das pe los alu nos da tur ma de $6^{\text {a }}$ sé rie ob servada por nós.

Efetivamente, observa-se que os quatro alunos com bom nível de aproveitamentotêm tendência a se associarem a alunos com nível de de sem penhose melhan te ou a alu nos mé di os e, so men te em um caso, a um alu no com fra co rendimento escolar. Paralelamente, os alunos com grandes dificuldades de aprendizagem têm muito mais tendência a se associarem a alu nos do mes mo nível ou de nível mé dio. Estes fazem tam bém uma es co lha pri o ri tá ria no seio de sua ca te go ria de po si ção es co lar. Além dis so, os alunos calmos declaram que, na turma, é mais freqüente fazerem amigos en tre os colegas mais calmos, en quan to os alu nos "ba gun ceiros" fazem amigos entre os "bagunceiros". As observações no decorrer das aulas confirmam o papel de reforço positivo ou negativo das ami za des em re la ção à es co la ri da de. Assim, na turma de $6^{a}$ sé rie a ami za de en tre Cé li ne e Angélique - aliás, alu nas com gran des di fi culda des de apren di za gem e re bel des - fa vo re ce o desenvolvimento de um comportamento antiescolar que, na verdade, é o oposto do que se ve ri fi ca na tur ma de $7^{a}$ sé rie no que diz res pe ito à amizade entre Ahmed e Nacer, que são ambos alunos com bom nível de aproveitamento, calmos e estudiosos. Aliás, entre as respostas da das pe los trin ta e seis alu nos in terrogados, somente Nacer evoca a homologia das atitudes escolares como critério de es co lha dos ami gos:

- Será que é importante que o colega more per to de sua casa, ou você po de ria ter um bom co le ga que mo ras se lon ge?

- Per to, isso tem van ta gens.

- ...? Por exem plo, Ahmed mora lon ge de tua casa?

- Não.

- Ese, por exem plo, Ahmed mu das se de casa, será que ele seria sempre um bom colega se você o en con tras se me nos ve zes?

- Com certeza.

- ...? E se você viesse a encontrar um aluno que mo ras se per to, será que ele po de ria tornar-se um ami go me lhor do que Ahmed?

- ... Não sei.

- lsso de pen de ria de quê?

- De seu com por ta men to.

- ...? Então, o que seria necessário em seu comportamento para que ele fosse um bom ami go, um ami go me lhor do que os ou tros? - Que não fos se ba gun ce i ro... que ele fos se sério. E que não se ofen des se logo, é isso.

(Na cer, $\left.7^{\mathrm{a}} \mathrm{F}\right)$

No en tan to, uma aná lise mais de ta lha da das ami za des re ve la que essa vi são pode mostrar-se simplista demais, principalmente no caso dos jo vens ori un dos da imi gra ção. É evi dente que alguns alunos - tais como Mehdi na tur ma de $7^{\text {a }}$ sé rie - le vam de al gu ma for ma uma vida du pla. Com efe i to, ape sar de ser o melhoralu no da tur ma e fa zer con ver gir to das as nossas observações para a imagem de um alu no aten to aos pro fes so res, bas tan te cal mo e muito bem integrado ao grupo dos alunos com bom nível de aprovei ta men to, Meh di tem 
um grande ami go no ba ir ro que está no co lé gio, mas foi en ca mi nha do a uma tur ma es pecial des ti na da aos alu nos que cri am gra ves pro blemas de dis ci pli na. Além dis so, nos dias de aula, man tém con ta to com os co le gas de tur ma, enquan to no fim de se ma na de di ca-se a ati vi dades, em particular, o futebol, com outros três co le gas do ba ir ro mais ve lhos que fre qüen tam um liceu profissional. Tal situação representa ainda melhor o caso de Nabil, outro aluno da tur ma de $7^{\text {a }}$ sé rie: ape sar de seu com por ta mento agi ta do na sala de aula, tem ob ti do no tas superiores às da maior parte dos colegas; no en tan to, em com pa nhia de um ami go, alu no da $8^{\text {a }}$ sé rie, re a li zou três as sal tos à mão ar ma da à far má cia do ba ir ro no de cor rer do ano em que estivemos observando sua turma. Essa dissociação re la tiva en tre a so ci a bi li da de es co larea so cia bi li da de de ba ir ro é fa vo re ci da - em particu lar, no caso de al guns alu nos de ori gem norte-africana ou africa na - pelo pre cá rio con tro le dos pais em re la ção à es co lha dos ami gos; aliás, estes raramente são recebidos em casa dos colegas.

Con tudo, po de mos formulara ques tão de sa ber o que se pas sa com as re la ções de ami za de e de ca ma ra da gem no pla no, não da tur ma, mas do colé gio. Um gran de nú me ro de alu nos que se be ne fi ci am do re gi me de se mi-internato sen tam-se na can ti na ou pas se i am no pá tio de re cre io com uma par ce la, pelo me nos, dos colegas de turma. Todavia, a análise dos grupos que incluem o maior número de tais colegas per mi te afir mar que, na sua ma i o ria, se tra ta de agru pa men tos de alu nos com nível bom ou médio de apro ve i ta men to, que fa zem par te da ca te go ria dos “pró-escola”, cu jas con ver sa ções e atividades (preparação de deveres, revisão de exercícios, leituras) gi ram, em gran de par te, em tor no dos es tu dos e da vida da tur ma. Entre es ses gru pos, en con tra mos o duo mais "sé rio" da tur ma de $7^{\text {a }}$ sé rie - Ahmed e Na cer - que, be ne ficiando-se do regime de semi-internato, freqüentam uma das atividades propostas pelo estabelecimento fora da sala de aula: o clube de leitura. Em compensação, os grupos for ma dos por uma ma i o ria de mem bros que não fazem parte da turma dedicam-se, de preferên cia, a ou tras ativi da des: con ver sa ções não es co la res, fu te bol, tê nis de mesa ou saké, atividadesilícitas no es paçoescolar (fu mar, subir os mu ros, pra ti car di ver sos trá fi cos). Além dis so, se atra vés des ses gru pos os alu nos re en con tram, na tural men te, cole gas que fo ram encaminhados a outras turmas, a situação é bastante diferente con for me se tra te de alu nos do mes mo ní vel ou de alu nos que ti ve ram de re pe tir uma ou vá ri as sé ri es, ou fo ram en caminhados a turmas específicas destinadas aos alunos que sentem mais dificuldades de aprendizagem ou são mais "bagunceiros": essa é a situação dos alunos da turma de $7^{\mathrm{a}}$ série contrat "que constituem a companhia pre fe ri da de Sa mi ra, alu na com fra co de sempenho escolar e integrante do grupo das “revoltadas" da tur ma de $7^{\text {a }}$ F. Com efe i to, pode-se aven tar a hi pó te se de que, nes te úl ti mo caso, exis te a pos si bi li da de de um ní ti do crescimen to da orien ta ção an ties co lardos alu nos.

Além dis so, im por ta ob servar que, para um gran de nú me ro de alu nos (qua se me ta de dos alu nos do co lé gio e das duas tur mas observadas), o tempo da sociabilidade no colégio é bastante reduzido porque eles não al mo çam na can ti na. Tal si tu a ção é o re sul ta do de res tri ções fi nan ce i ras: como a aju da do Esta do deixou de ser atribuída aos es ta be le cimentos de ensino, é necessário que, correspondendo ao desejo manifestado pelos adoles cen tes, as fa mílias so li citem tal be ne fício. Ora, com ra ras ex ce ções, nas duas tur mas observadas, os externos são, sobretudo, alu nos com dificuldades de aprendizagem ou alu nos “ba gunceiros”, sem dúvi da por que, em

11. Trata-se de classes especiais, formadas por um número reduzido de participantes (no máximo 15), criadas para os alunos que sentem dificuldades de aprendizagem, mas continuam mantendo uma predisposição positiva em relação à escola; com eles, os professores estabelecem uma espécie de contrato de trabalho (N.T.). 
geral, são ori un dos de fa mílias me nos fa vo re cidas; além dis so, como vi vem com di fi cul da de a ex pe riên cia es co lar, po de-se su por que se li mitam a passar no estabelecimento de ensino o tem po es tri ta men te ne ces sá rio. Ora, o fato, na apa rên cia ba nal, de vol tar em casa para al mo çar - que, mu i tas ve zes, em ou tros con tex tos de es co la ri za ção, é o privi lé gio de alu nos pro ve nien tes de me i os abas ta dos, cu jas mães não têm uma atividade profissional - apresenta aqui conseqüências não negligenciáveis: ao voltarem em casa, os alu nos re for çam as re la ções de amizade com os vizinhos de bairro, de preferência os colegas de turma, perambulam pela rua e en volvem-se em ativi da des não-escolares, lí ci tas ou ilí ci tas, che gam atra sa dos ou, en tão, não com pa re cem às pri me i ras au las da tar de e, em breve, deixam-se arrastar por uma lógica que, potencialmente, tende a afastá-los ainda mais da escola.

\section{A sociabilidade nas "turmas fracas": segregação, anomia e “deriva”}

No en tan to, em bo ra as opi niões e as amiza des dos alu nos de ixem en tre ver o pa pel, di reto e indireto, da escola na emergência de gruposdesviantes, é a análise da sociabilidade dos alu nos nas res pec ti vas tur mas que per mi te compreender melhor a cons tru ção de uma di nâ mi ca "desvi an te". Para al can çar tal obje tivo, decidimos observar duas "turmas fracas", ou antes, duas turmas formadas por alunos com baixo desempenho escolar e outros de nível médio de aproveitamento. ${ }^{12}$ Vários trabalhos re cen tes mos tra ram a im por tân cia da se gre gação interna das turmas no âmbito do colégio "único". ${ }^{13}$ A cons ti tu i ção de tais tur mas de sempe nha um du plo pa pel nos co lé gi os da pe ri feria, como o "Ver la i ne". Por um lado, tra ta-se da possibilidadedeadministraraheterogeneida de do público pela criação de agrupamentos de alunos que apresen tem uma cer ta ho mo ge neidade em termos de "nível" e evitar situações explo si vas em ma té ria de dis ci pli na. Mas, por outro lado, trata-se igualmente de criar turmas que, mes mo não pre ten den do al can çar o grau de ex ce lên cia, dêem aos pais dos me lho res alu nos a ga ran tia de que têm um ní vel de rendimen to su ficien temen tebomeconsistente para receberem os filhos (Zanten, 1996; Broccolichi e Zanten, 1997; Ball e Zanten, 1998). Ora, como ti ve mos a opor tu ni da de de verificar no colégio "Verlaine”, nas "turmas fra cas" (que são a con se qüên cia qua se au to mática da constituição de "turmas fortes" nesses con tex tos dees cola rização) en con tramos, ge ral men te, não só um nú me ro ma i or de repetentes e de alunos com dificuldades de aprendizagem, mas também uma proporção ma i or de alu nos cujo pa tro ní mi co é de ori gem es trangeira, sen do que a ma i o ria é cons ti tuída por meninos (Payet, 1995).

Todavia, tivemos a sorte de observar duas turmas dotadas de dinâmicas bastante dis tin tas, o que per mi te apro fun dar os fa to res em ação nos pro ces sos de so ci a bi li da de es colar nas "tur mas fra cas". Na tur ma de $6^{\text {a }}$ série, re ina um cli ma próxi mo da "de sor dem anô mica” em sua ver são me nos dra má ti ca, em que a apatia, ou seja, o reduzido grau de energia que é consagrado ao estudo pelos alunos, mis tu ra-se com a ano mia, ou seja, a de sor ganização do grupo-turma (Testanière, 1967). Com efe i to, pa re ce que os alu nos sen tem pouca motivação pelos estudos ou são "agitados”, ou as duas coisas ao mesmo tempo. Aliás, na turma, não existem líderes, quer se

12. No entanto, por razões de comodidade, utilizamos em nossas análises uma classificação em "fortes", "médios" e "fracos" que só é válida no interior de cada turma ou nas turmas do mesmo tipo. De fato os alunos a que daremos a qualificação de "fortes" são, antes, alunos médios; os "médios" são, de preferência, alunos fracos; e os "fracos" são alunos com grandes dificuldades de aprendizagem.

13. Assim, o estudo estatístico elaborado a partir de uma amostra de colégios da circunscrição administrativa do ensino de Dijon estima que até $80 \%$ desses estabelecimentos instituem - seja de maneira moderada, seja, quase sempre, segundo uma estrutura claramente hierarquizada - uma enturmação segundo 0 critério do desempenho discente (Duru-Bellat e Mingat, 1997). 
tra te de lí de res pró-escola que ar ras tam os ou tros para uma relaçãopositiva com a aprendiza gem, ou de lí de res an ti es co la que fa vo re cem a de sor dem co le tiva e a con tes ta ção da or dem es co lar. Ape sar de ser apre ci a do por al guns colegas com bom nível de aproveitamento, o melhor de to dos eles, Nel son, de ori gem por tugue sa, com ca rá ter tí mi do e en fe za do, é per cebi do como "me ti do" pe las me ni nas que têm um nível de rendimento médio ou fraco, além de ser objeto de numerosos trotes por parte dos outros alunos, em particular, por parte de Azdin, de ori gem norte-africana, que é una nime men te re co nhe ci do como o alu no mais "bagunceiro" da turma. Mas Azdin, cujas notas baixas não refletem suas qualidades intelectuais, também não é um líder porque não se limita a incomodar os professores, mas igual mente a prejudicar os outros alunos. Em um boletim escolar, chega mesmo a ser descrito como "pe ri go so para os co le gas".

Além dis so, nes ta tur ma, os me ni nos e as meninasintera gem, mui tasvezes, em peque nos gru pos que man têm en tre si re la ções de ri va li dade, denunciando-se mutuamente como "ba gun ce iros" ou “la drões”. Esses sub gru posre cons ti tu ídos no Grá fi co 1 a par tir de nos sas observações e das declarações dos próprios alu nos - es tão es tru tu ra dos, de for ma mu i to cla ra, em fun ção da re la ção com os va lo res e nor mas es co la res. Entre os me ni nos, os "apli cados” são alunos de nível bom ou médio e, de preferência, calmos e atentos; os "agitados” são alunos de nível médio, tagarelas, mas não forçosamente desordeiros. Entre os “durões”, encontramos um aluno com nível de aprove i ta men to bom (Ka rim), ou tro mé dio (Kha led) e um fra co (Azdin), mas que se ca racterizam por sua insolência em relação aos pro fes so res, por seus dons de "ba gun ce i ros" e por sua capacidade para impor respeito pela for ça jun to dos ou tros alu nos. Um jo vem en contra-se bastante isolado: trata-se de Franck, alu no com baixo de sem pe nho es colar, mas calmo e bastante crítico em relação aos colegas “brin calhões” ou mais “du rões”. Entre as meninas, as "sérias" são alunas de nível bastante bom ou mé dio, mas que, para re to mar a ex pres são de Char lot et al . (1992), ain da estão mobilizadas pelos estudos; as

Grá ficol. Redes de sociabilidade Tur ma de $6^{\mathrm{a}}$ sé rie

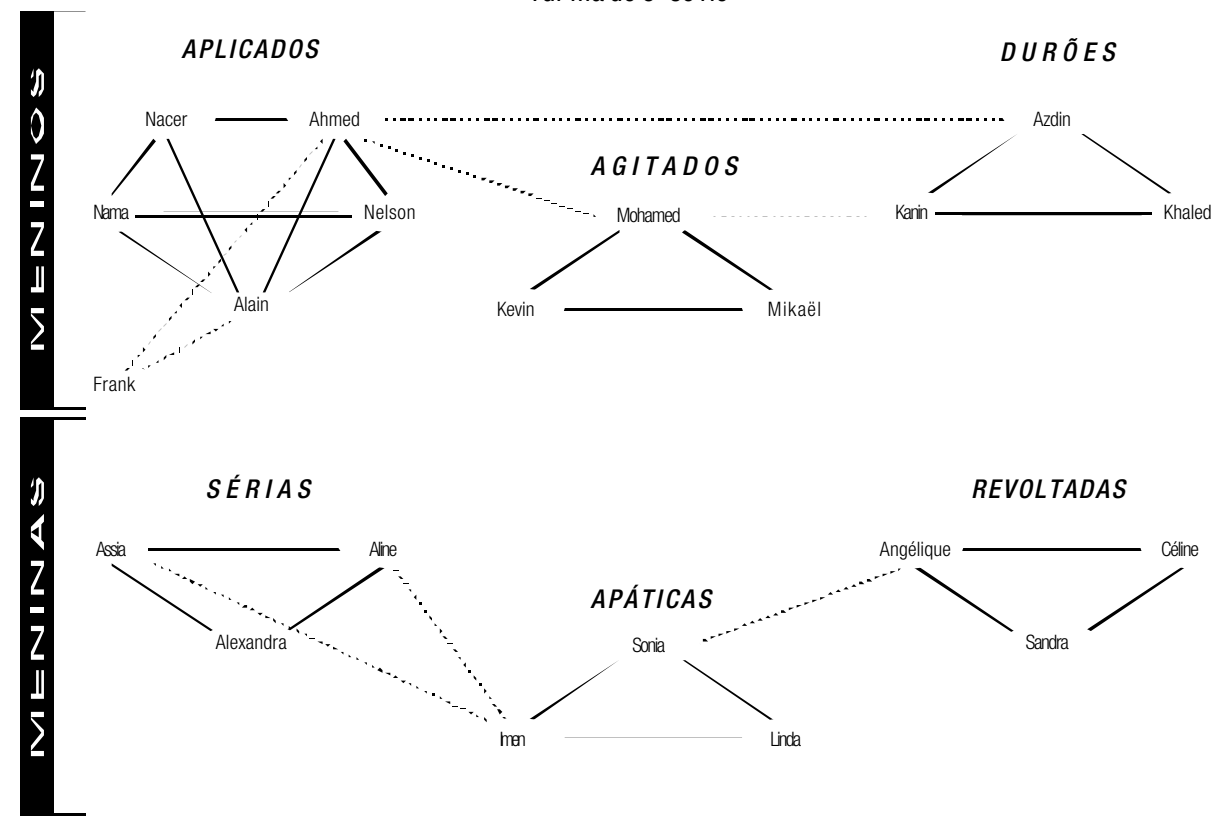


“apá ti cas” são más alu nas e cal mas, mas in di ferentes à aprendizagem e aos professores; por úl ti mo, as "revol ta das" são más alu nas que têm comportamentos antiescolares de recusa ou desordem. No entanto, nenhum grupo consegue im por uma di nâ mi ca, seja em que sen ti do for, em ra zão de seu ta ma nho re du zi do e da incapacidade de seus membros em contrair alianças tá ti cas que per mi tam le var a tur ma a se di re ci o nar para a es cu ta aten ta dos pro fes sores ou para a verdadeira bagunça (Pollard, 1985).

A si tu a ção na tur ma de $7^{\text {a }}$ sé rie, ob servada por nós, é completamente diferente. Com efeito, segundo a opinião geral, reina aí um bom cli ma en tre os alu nos; a ma i or par te de les chega mesmo a declarar sua preferência por esta tur ma, em vez da tur ma do ano an te ri or. Esse entendimento traduz-se, principalmente, em ter mos es co la res pelo im por tan te de sen volvi men to das prá ti cas de aju da mú tua en tre alunos. Não só estes emprestam uns aos outros, com maior facilidade, folhas, canetas, réguas ou livros, mas fa zem circularsis te ma tica men te a có pia dos exer cí ci os e de ve res de casa já re solvi dos a fim de fa ci li tar a vida dos co le gas. Tais prá ti cas, que pu de mos ob servar em nu me ro sas ocasiões, são mencionadas, sem qualquer reserva, por um grande número de alunos que, salvo raras exceções, as consideram absolutamen te nor ma is; além dis so, a ques tão de sua le gi ti mi da de em re la ção aos va lo res e nor mas da instituição concernentes a caráter individual do trabalho só é formulada por algunsalunos com bom nível de aproveitamento e, neste caso, quase sempre sob a for ma de des dém:

- Será que você acha que, do pon to de vis ta do tra ba lho es co lar, há bom en ten di men to na turma? Será que, nes te as pec to, exis te aju da mú tua en tre os alu nos?

- Sim. So bre tu do em re la ção aos deve res [sor riso largo].

- Por que você diz isso sor rin do? Por essa aju da mútua ser exagerada?
- Bom, sim... einh... Um aluno faz o dever e passa a cópia da resolução para dez; depois quan do o pro fes sor se dá con ta...

- E, com as provas ora is, acon te ce a mes ma coisa? Ou...

- Não, [a gen te ?] não fa ria isso com as pro vas ora is, é evi den te. Não, isso li mi ta-se aos de veres... einh...

(Christelle, $7^{\text {a }} \mathrm{F}$ )

Essa predisposiçãopara a aju da mútua - não ex clu si va das "tur mas fra cas" - re sul ta, de um lado, do desenvolvimen to de uma atitu de mais uti li ta ris ta di an te das de man das da instituição,à me di da que os alu nos avan çam em sua es co la ri da de no co lé gio. 0 que pa re ce importante é ter feito o trabalho solicitado, sejam quais forem os meios utilizados para ela bo rá-lo, mes mo sem ter apre en di do o sentido para si (Charlot et al., 1992; Barrère, 1997).

- Será que você acha que existe, realmente, aju da mú tua na tur ma?

- Bom, sim, eles se aju dam mu i to... einh... Por exem plo, quan do a gen te, quan do a gen te não tem folha de papel, existem alunos que não dão por que são pães-duros, mas caso con trá rio, a gen te dá as fo lhas, é as sim. E einh... sim, a gen te se aju da... por exem plo, em re la ção aos de ve res einh... A gen te ex pli ca àque le que não com pre en de, a gen te ex plica-lhe como se deve fazer e depois... tudo mais. Desta forma, os profes so res acham quevocêfez os exer cíci os... É as sim.

(Na bil 7aF)

Mas o que, sem dú vi da, cons ti tui so bretu do a es pe ci fici da de das "tur mas fra cas" neste aspecto é a pressão, direta ou in direta, do gru po dos pa res, de um “nós” que co me ça a se formar contra a instituição (Dubet e Martucel li, 1996); nin guém tem a ou sa dia de ofe recer resistência a tal postura, até mesmo quan do as prá ti cas de aju da mú tua im pli cam 
Grá ficoll. Com quem você gos ta ria de es tu dar?

Tur ma de $7^{\mathrm{a}}$ sé rie

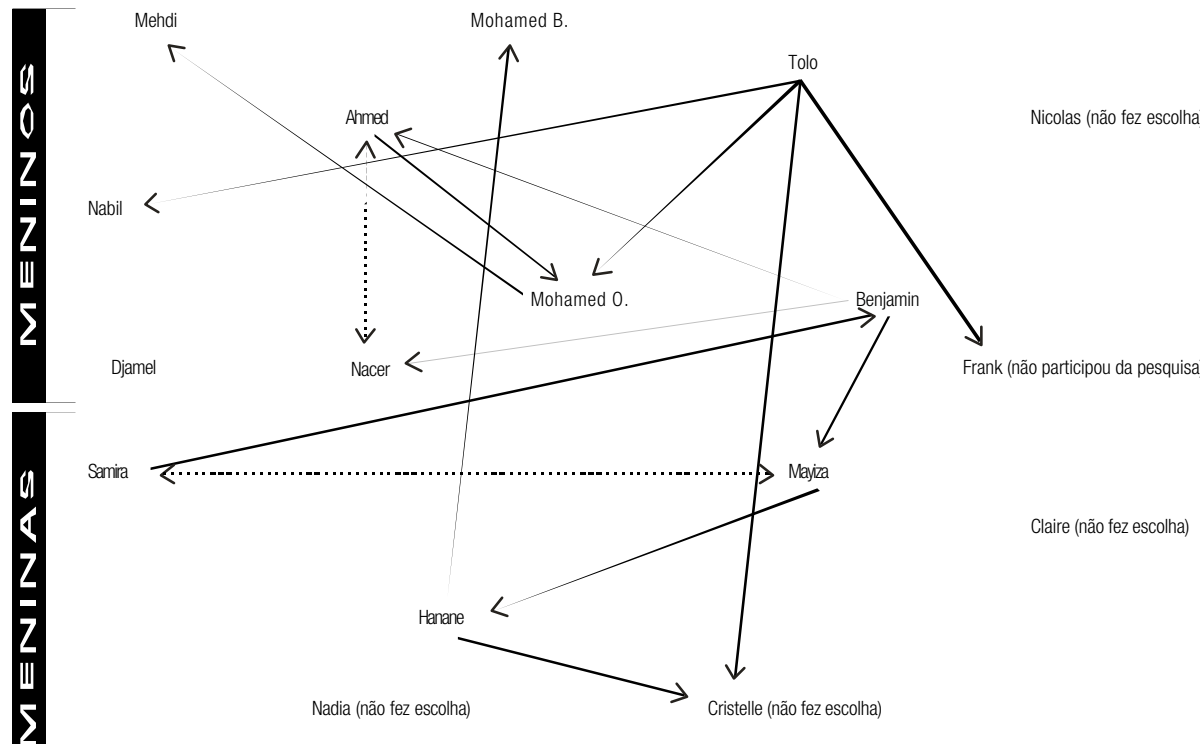

Elisa (não participou da pesquisa)

conseqüências negativas para o devir escolar individual:

- E você acha que quan do um alu no faz o de ver e dis tri bui có pi as aos ou tros, ele en tre ga a todo o mun do, ou será que, às ve zes, exis tem alu nos que são de i xa dos de lado, a quem não é en tre gue a có pia dos de ve res já re sol vi dos?

- Não. A gen te [ina u dível] já pe diu: "Você me de i xa ver a có pia" e de po is isso éle gal. [Sor ri so] Já que você o fez. Mas, às ve zes, é in jus to; como eles se dão con ta de que os exer cí ci os fo ram copia dos, ficam conven ci dos de que vocêé que copi ou e de po is...

- Portanto, será que as cópias circulam por todos? Não haverá alunos que dizem: "Você pode mostrar-me sua cópia?" e acabamsen do rejeita dospelo ou tro?

- Não.

- Assim mes mo?

- Oh! por mim, en tre go-lhes... einh... e de po is é isso. Na medida em que o fiz.

(Christelle, $7^{\mathrm{a}} \mathrm{F}$ )
Além disso, observa-se outro exemplo do desenvolvimento de uma orientação utilitarista quando é perguntado aos alunos com quem gostariam de estudar na turma. Como mostra o sociograma do Gráfico 2, os alunos mais populares deste ponto de vista são os me lho res alu nos: Meh di, Ahmed, Na bil, Mohamed 0. e Djamel, ou seja, os cinco melhores alunos da turma recebem cada um quatro votos; enquanto Mohamed B., Christelle e Nacer, que têm um nível de aproveitamento menos bom, recebem, cada um, três votos. Em compensação, os alunos que têm mu i tas di ficul da des de apren diza gem - tais como Ni co las, Na dia ou Cla i re-, ou que são mé di os, mas mu i to de sor de i ros, tais como Tolo, não obtêm qualquer voto. Paralela men te, ob serva-se que os alu nos com bom nível de desempenho - com exceção de Hanane que desejaria estudar com Samira escolhem exclusivamente, como colegas ide a is para a pre pa ra ção do tra ba lho es co lar, alunos de nível igual. 
Além disso, apesar de continuarem a se ob servar à dis tân cia e, às ve zes, ocul ta rem até mesmo na tur ma as re la ções de ami za de - in clu sive, mais ex cep ci o nal men te, as re la ções de fler te que, al gu mas ve zes, man têm fora da es cola-, os alu nos dos dois se xos ace i tam me lhor que, neste ní vel, o "ofí cio de alu no" im pli que interações com os co le gas da tur ma, às ve zes, interações exigidas pela instituição, mas tam bém úte is para me lho rar as no tas, sem que seja ne ces sá rio che gar a ver da de i ras re la ções de camaradagem e amizade:

- E quan to a você, se tives se de par ti ci par de um gru po de tra ba lho, em de ter mi na da aula, com quem gos ta ria de es tu dar?

- Bom, a gen te fica mis tu ra do na tur ma, portan to... einh... quan do a gen te está em um grupo, às ve zes, a gen te está com me ni nos, ou tras ve zes, com me ni nas; bom, toda a gen te fica mistu ra da, é as sim. Não é por isso que a gen te vai dizer: "Não, não quero estudar com ele... " einh...... Não se está mais em $\mathrm{CP},{ }^{14}$ einh...

- E no ano passa do, isso acon te cia da mes ma for ma? Vocêteria es tu da do com qual quer um?

- Não. No ano passado, não. Porque, bom, einh... porque, bom, os colegas da turma não eram einh... não sei como explicar isso. Mas bom, na ver da de, os co le gas pen sa vam mais em implicar com as meninas do que... do que em aju da rem-se, é isso.

(Claire, $7^{\text {a }} \mathrm{F}$ )

- Se você ti ves se de for mar um gru po de tra ba lho com os co le gas da tur ma - por exem plo, um gru po de três ou qua tro alu nos - e se ti ves se a possibilidade de escolher, com quem preferiria estudar?

- (...) Como direi..., as meninas, bom, einh... não é por que a gen te não que i ra es tu dar com as me ni nas, mas por que elas pre fe rem... fi car com as co le gas, bom, para co men ta rem co i sas einh... de me ni nas, não é? Isso não é nos so pro ble ma.É tudo. Se não, a gen te pode... eu po de ria es tu dar com as meninas da turma, bom, de qualquer modo, não, isso da ria no mes mo. Com me ta de da tur ma - não é? -, eu po de ria es tu dar.

(Mo ha med, $7^{\text {a }} \mathrm{F}$ )

Po de ría mos pen sar que tal cli ma é fa vo rá vel ao de sen volvi men to, se não de uma rela ção po si tiva com a apren di za gem, pelo me nos de uma ati tu de su fi cien te men te "pró-escola" para po der aju dar os alu nos a perse gui rem, no colé gio, uma es co la ri da de ade qua da quelhes forneça bases suficientes para serem bem-sucedidos nos es tu dos no li ceu. De fato, revela-se que a "7a F" é também uma turma em que re i na uma for te "ba gun ça" mu i to mais re cor ren te e vi sível do que na “6a"D”. Tal si tuação re sul ta de vá ri os fa to res. Por um lado, a maior parte dos alunos - incluindo os mais "sérios", com exceção, talvez, de Nacer e Ahmed - de fi nem-se a si mes mos como "um pouco agitados”. Portanto, como em certas turmas, não existem, de um lado, alunos aplicados e, do outro, alunos bagunceiros. Essa com bi na ção do es pí ri to de se rie da de com o espírito de brincadeira é reivindicada, até mesmo por al guns alu nos com bom ní vel de aprovei ta men to, como uma es pé cie de iden tidade ligada ao tipo do estabelecimento de ensino:

- Pelo con trá rio, será que você acha que, na tur ma, exis tem alu nos que são sem pre sé ri os, aplicados...?

- Sim. Exis tem alu nos as sim na nos sa tur ma.

$-\ldots$ ?

- Mas... não poderia haver aí alunos sérios, por obri ga ção; às ve zes, a gen te di ver te-se. É isso. Eles não podem ser sérios, sérios, sérios todo o tem po.

- E por que ele não pode ser sé rio todo o tem po?

- Porque se fosse sério, mesmo sério todo o

14. Sigla de Cours Préparatoire, correspondente ao $3^{\circ}$ período da pré-escola ou classe de alfabetização (N.T.). 
tem po, ele não es ta ria nes te co lé gio. Você es taria em um co lé gio mais dis ci pli na do. É isso.

(Na bil, ${ }^{\mathrm{a} F}$ )

Por ou tro lado, a for te so li da ri e da de que re ina en tre o gru po de alu nos com bom nível de desempenho, meio-sérios, meio-agitados, im pe de os pro fes so res de uti li za rem a con cor rência individual para evitar que os alunos se unam contra eles. Se, entre professores, existem di fe ren ças - que não se rão evo ca das aqui no que diz respeito à capacidade de resistir à de sor dem, a ma i or par te de les é obri gada a insta u rar "tréguas" no com ba teco ti dia no con tra a in disciplina:eles são le va dos a to le rar o rui do, as brinca de iras e nu mero sas "ba gun ças" du rante a aula (Rey nolds, 1976).

Esse cli ma é apre ci a do pe los alu nos porque, en tão, eles re en con tram na tur ma o es pírito de brin ca de i ra que, aliás, ani ma as per mu tas com os co le gas no co lé gio e no ba ir ro (Le poutre, 1997); ora, tal espírito permite-lhes com bater o enfado e afirmarem-se diante dos professores (Woods, 1991). Mas, paralelamente, es ses mes mosalu nos, in clu in do uma par ce la dos mais “agi ta dos", de plo ram for te men te que as "bagunças" os impeçam de se concentrar e realizarcorretamente o trabalho escolar:

- Gos ta ria que você me dis ses se o que pen sa a res pe i to do cli ma na sala de aula.

- Einh... é bom, mas acho que há me lhor, po de ria ser me lhor.

- Como as sim? Me lhor em ou tra tur ma ou...

- Não, melhor como clima. Às vezes, existe... exis tem alu nos que im pe dem os ou tros de es tudar. E einh... é isso mes mo, isso es tra ga tudo.

(Meh di, 7a F)

- Como é que você acha o cli ma na sala de aula?

- Ba gun ça do de ma is. A gen te brin ca de ma is. A gen te não pen sa em se guir os cur sos. Eles pre ferem brin car. E não me sin to à von ta de.

- Como as sim?
- É isso mes mo. Não é uma tur ma tran qüi la. Einh... a do ano pas sa do era um pou co me lhor, mas mes mo as sim... isso dá no mes mo. Acho que é uma turmatumultuada.

- Você pre fe ri ria es tar em ou tra tur ma?

- Sim. Mas em uma tur ma mais einh... mais tran qüi la, é isso. Que einh... em que os alu nos es tives sem com von ta de de es tu dar mais.

(Mo ha med 0., 7 ${ }^{\mathrm{a}} \mathrm{F}$ )

Essa situação tem a ver com o fato de que os alunos, in clu in do os mais es tu di o sos, vi vem a vida de tur ma sob a for ma de uma al ter nân cia não con tro la da: por um lado, sen tem o de sejo de res pe i tar as nor mas es co la res e con servar o es pí ri to de se ri e da de; e, por outro, preten dem rea gir ao desen co raja men to e en fa do pro du zi dos pela pres são es colar, as sim como à di fi cul da de de per ma ne ce rem "mo bilizados" (Rochex, 1995; Dubet e Martucelli, 1996):

- E por que mo tivo, às ve zes, você é agi ta do? - É... tra ta-se de uma pe que na de pres são, não sei. Às vezes, estou cheio, estudar o tempo todo... é isso.

(Meh di, 7ªF)

- Qu an do es tou com von ta de de es tu dar, não gosto, einh... de ruído. E quando não estou afim de es tu dar, aí, gos to da agi ta ção da sala de aula.

$-\ldots$ ?

- Mas isso de pen de dos dias. Pron to. É tudo.

- E isso de pen de dos dias einh... se gun do seu hu mor ou se gun do...?

- Sim, mu i tas ve zes, se gun do meu hu mor.

- Em de cor rên cia do que aca ba de acon te cer com você ou com o que...?

- Não ne ces sa ria men te, quan to me sin to bem, quan do es touàvon ta de, aí, fran ca men te, posso es tu dar, mas quan do não me sin to bem, então... fico sem von ta de de es tu dar.

(Sa mi ra, $7^{\mathrm{a} F}$ ) 
Em al guns alu nos, essa di vi são dá lu gar a uma atitudein dividual de re tra imen to. No entanto, quase sempre, conduz a manifestações públicas de revolta que desencadeiam um trans tor no mui to ma i or para a ins ti tu ição. Neste caso, o cli ma aca ba vi ran do "de sor dem anô mica” em sua versão mais dramática (Tes ta niè re, 1967). Tal de sor dem é o opos to da estratégia consciente e da revolta deliberada; apre sen ta-se aos alu nos, de pre fe rên cia, como uma fatalidade. Com efeito, a pressão institucional e a pres são do gru po de co le gas pro duz um sentimento de irresponsabilidade e impotên cia. "A gen te é ar ras tado" diz a ma i o ria dos alunos:

- Bom, você é obrigado a... porque... porque você einh... é, você é pego pelos outros, por exem plo, eles fa zem go za ções, en tão, você não vai fi car ca la do. E os ou tros, eles fa zem go zações, en tão, você é obri ga do a fa zer o mes mo.

(Na bil, $\left.7^{\mathrm{a}} \mathrm{F}\right)$

- Eles dizem gra ce jos na sala de au las... tudo mais; em se gui da, a gen te res pon de e... isso acaba sem pre por uma hora de pro va oral, ou co i sa pa re ci da.É di fícil de... re sis tir. Àsve zes, a gen te con se gue isso, mas nem sem pre...

(Meh di, $\left.7^{\mathrm{a}} \mathrm{F}\right)$

- Ago ra, di vir to-me de ma is com os ou tros. Vai ser ne ces sá rio que eu faça um es for ço para acabar com isso; aí, tenho, desde einh... desde einh..., es pere, des de se gun da ou quar ta-feira, ten tei... ten tei aca bar com isso. Bom, te nho tenta do, faço o que pos so; caso con trá rio, é di fí cil, mes mo as sim, ten tar de ixar de diver tir-se [sor riso] (...) Bom, no iní cio do ano, eu... eu ain da me con tro la va, mas ago ra, não con si go fi car tranqüilo. Minhas notas baixaram por causa disso e... é por isso.

- No iní cio, você di zia: "vou es tu dar, vou ser sério" e tudo, e...

- Exa to. Ago ra, não con si go con tro lar-me. No segundo trimestre, eu não conseguia contro- lar-me. É di fí cil de ma is. Ao ver uma tur ma que se diver te o tem po todo e... os pro fes so res que não di zem nada...

- Se você es ti ves se ao lado dos alu nos sé ri os como Ahmed ou Nacer, você pen sa que te ria me nos tên den cia para a brin ca de i ra ou...

- Com cer te za. Mas, não se tra ta de es tar senta do ao lado de al guém... É a agi ta ção de toda a tur ma. É isso que me leva a fa zer go za ções ao mes mo tem po com eles.

(Mohamed 0., 7a F)

Mas se os alunos estão conscientes da influência que sofrem por parte dos colegas, nem por isso pen sam em in cri mi ná-los di re tamen te por que, por um lado, o sen ti men to de solidariedade entre eles é mais forte do que aque le que os liga à ins ti tu i ção es co lar, e, por ou tro, a im por tân cia que as su me ojul ga mento dos colegas leva a evitar as condutasque viessem a suscitara desa provação deles.

- Os ou tros alu nos fi ca ri am ir ri ta dos se você não fi zes se como eles?

- Bom, não se tra ta de fi ca rem ir ri ta dos, mas eles próprios iriam sentir-se rejeitados se eu não fi zer go za ções, já que sou o mais for te da turma.

(Mohamed 0., 7ªF)

- E como é que você se con si de ra: uma alu na dis ci pli na da ou um pou co agi ta da?

- ... Oh! eu sou bem-comportada em de ter minadas aulas, sabe? Somente em uma aula é que não sou com por ta da, é isso (...)

- E, nes se caso, é por ca u sa de...?

- De nin guém. Só que vejo... vejo todo o mun do fa lan do, en tão, sin to von ta de de ir atrás, por que não quero... por que não te nhovon ta de de ser consideradaumamenina-modelo.

(Claire, $7^{\mathrm{a}} \mathrm{F}$ )

Esse clima torna-se, progressivamente, algo se me lhan te ao es ta do de "de riva" ( drift) descrito de forma meticulosa por Matza 
(1964). Nes te caso, a sala de aula tor na-se um espaço propício para o desenvolvimento de uma cul tu ra da de lin qüên cia, ou seja, um meio no qual certas transgressões da norma aparecem como inevi tá ve is, até mes mo como le gí timas, tan to mais que os pro fes so res re ve lam-se im poten tes em limitá-las.

\section{Relação com a escola e relações interétnicas: "grupinhos influentes", fluidez e conflitos}

A constituição desse meio desviante apóia-se, como acabamos de ver, em relações de pre fe rên cia po si tivas en tre alu nos na tur ma, o que implica, de maneira quase automática neste contextoamplamente multiétnico, bons con ta tos en tre alu nos de di fe ren tes ori gens. No en tan to, será que exis tem "gru pi nhos in flu entes" desvian tes cons ti tuídos em uma baseét nica? Des te pon to de vis ta, a si tu a ção apa re ce de modo bas tan te di fe ren te nas duas tur mas es tudadas. Na turma de $6^{a}$ série, formada por dez alu nos de ori gem ar ge li na, três de ori gem africana, uma aluna de origem indiana e dois de origem portuguesa, além de cinco franceses “da gema”, é pos sível ob servar nu me ro sas relações interétnicas entre os alunos (Gráfico 1): qua tro sub gru pos em seis que man têm re la ções diversificadas com a escolaridade são multiétnicos. Com efeito, entre os "aplicados", en con tra mos dois jo vens de ori gem ar ge li na, um de ori gem afri ca na, um ou tro de ori gem por tugue sa e um fran cês "da gema"; en tre os "agi ta dos”, existe um de origem argelina, outro de origem portuguesa e um francês. Quanto às me ninas "sé ri as", Assia, de ori gem argelina, entende-se muitíssimo bem com Alexandra e Aline, am bas fran ce sas "da gema"; por sua vez, en tre as me ni nas "revol ta das”, Céline, francesa “da gema”, tem como me lhor ami ga Angé li que que é de origemindiana, além de se entender bem com San dra, de ori gem afri ca na. Em com pen sa ção, os gru pos dos “du rões” e das “apá ti cas” são compostos, respectivamente, por três me ni nos e três me ni nas de ori gem ar ge lina. Se esses agrupamentos obedecem, em parte, a uma ló gi ca arit mé ti ca, uma vez que os alu nos argelinos for mam o grupo "ét nico" 15 mais am plamente representado na turma, é evidente que a afi ni da de "ét ni ca" in te ra ge, aqui, com a não-adesão à ordem escolar, sem que seja possível determinar facilmente o sentido da relação: a etnicidade servirá de ponto de apoio à revol ta dos me ni nos ou ao re tra i mento das meninas, ou será que essas atitudes con du zem osjo vens ori un dos da imi gra ção a se confinarem no grupo étnico de sua identidade?

Na tur ma de $7^{\text {a }}$ sé rie, tam bém mul tiét nica (onze alunos de origem argelina e um de origemmarroquina, um de origem africanae ou tro de ori gem asiá ti ca, um de ori gem por tuguesa e três franceses "da gema"), parece es tarem ação uma di nâ mi ca bas tan te diferente. Se, na tur ma, exis te um "gru pi nho in flu ente" com base ét ni ca, ele é tan to "pró-escola" quan to "an ti es cola". Comoéde mons tra do no Grá fi co 3, exis te um gru po de sete jo vens norte-africanos, qua se to dos de ori gem ar ge li na, que mantém relações estreitas na turma e exer ce atra ção so bre os ou tros alu nos. Tal si tuação pode ser explicada, em parte, pelos efe i tos da do mi na ção nu méri ca so bre as relações in te rét ni cas: o fato de fa ze rem par te do grupo "étnico" mais representativo da turma pode levar os jovens norte-africanos a se fe cha rem en tre si, sem de $i x a$ rem de cons ti tu ir o alvo de so li ci ta ções de ami za de por par te dos ou tros co le gas (Hal li nan e Smith, 1985). Mas, em parte, isso é assim também porque, pelo jogo das orientações educacionais adotadas

15. Na sequiência do texto, em parte, por razões de comodidade sem dúvida, contestáveis - utilizaremos o qualificativo "grupo étnico" para designar grupos nacionais, raciais e propriamente étnicos. As principais classificações (norte-africanos, negros, asiáticos, franceses "da gema"...) remetem às categorias utilizadas, com maior freqüência, pelos alunos e professores para distinguirem indivíduos ou grupos no espaço escolar; ora, tais categorias revelaram-se absolutamente pertinentes para esta análise. 


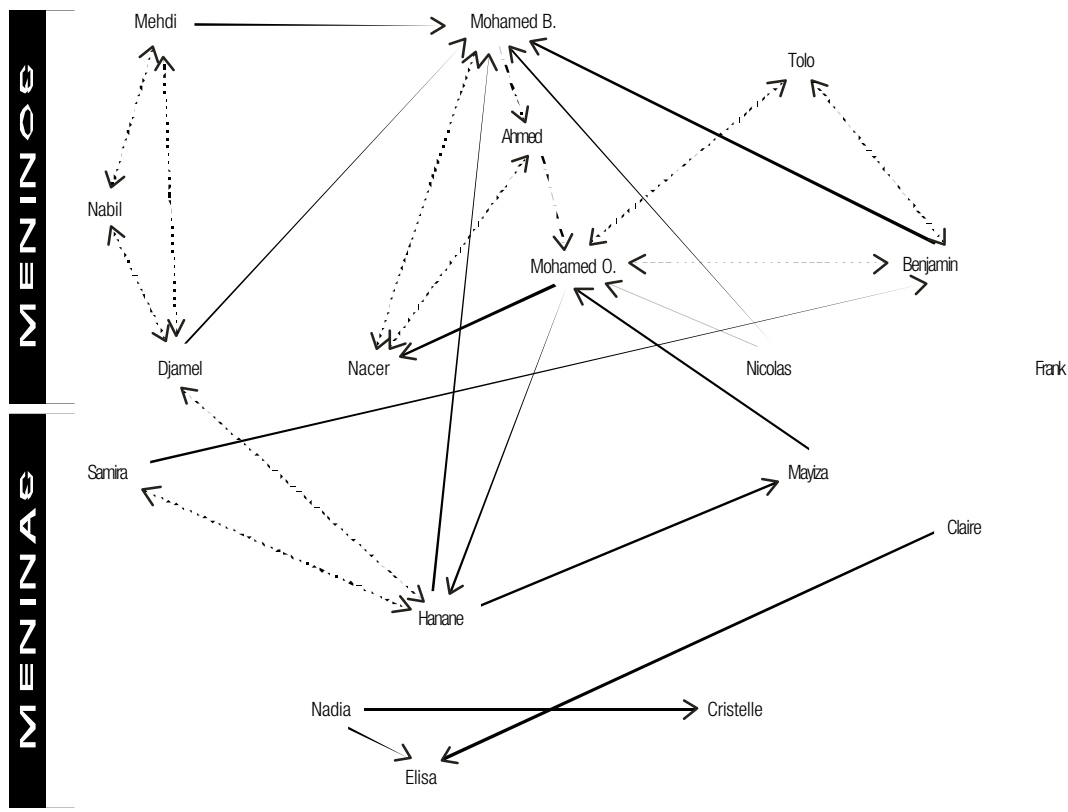

nas “tur mas fra cas”, eles en con tram-se aqui em posição de superioridade escolar. Com efeito, existem ele men tos que per mi tem afir mar que, em ra zão de seu com por ta men to, os jo vens de ori gem nor te-africana, com nível es co larigual, são en ca mi nha dos, com uma fre qüên cia ma i or do que os co le gas fran ce ses, a tur mas for ma das por alu nos com ba ixo de sem pe nho es co lar ( $\mathrm{Zi}$ rotti, 1980), o que pode ter como efeito paradoxal dar-lhes a possibilidade de ocupar, em ter mos de es ta tu to es co lar, uma po si ção do minante em tais tur mas. Mais aci ma, foi pos sível ob ser var que são es ses os alu nos ci ta dos, com maior fre qüên cia, como os co le gas com quem os outrosgostariam de estudar. Aliás, sua po pularidade repousa também na circunstância de que - com ex ce ção, tal vez, de Ahmed e $\mathrm{Na}$ cer - eles são "brin ca lhões", ou seja, alu nos que se situam no registro ora do "sério", ora da "brincadeira" (Pollard, 1985).

0 que se pas sa no co lé gio como um todo? Graças a nossas repetidas observações, pudemos constatar, entre os grupos de alunos que almoçam na cantina, que ficam parados ou pe ram bu lam pelo pá tio de re cre io, a exis tên cia de bandos, ou seja, associações bastante es tá ve is de alu nos da mes ma ori gem “ét ni ca”. No en tan to, nes ses gru pos, nem sem pre é fá cil es ta be le cer a dis tin ção en tre o que tem a ver com a ló gi ca de afi ni da des do tipo "ne o co munitário" - no âmago das quais ainda seria necessário iden ti fi car se a in fluên cia é pro venien te das tra dições fa milia res, dosmovimentos de revitalização étnica ou das interações estabelecidasno bairro - e o que se refere a outras lógicas, em particular, escolares. Assim, se pa re ce na tu ral as so ci ar a exis tên cia de agru pa men tos de alu nos asiá ti cos, na sua maioria de origem chi nesa, a tra ços cul tu ra is co muns, con vém ob servar que es ses alu nos e, principalmente, as jovens asiáticas - diferenciam-se, muitas vezes, dos colegas neste colégio da periferia por sua atitude atenta e cal ma na sala de aula. É, aliás, por tal mo ti vo que, raramente, esses grupos chamam a atenção dos professores. Outros bandos 
aproximam-se mais do modelo da subcultura desviante. No momento de nosso estudo de cam po no es ta be le cimen to, era o caso do grupo que ocu pa va uma mesa na can ti na: se gun do os dias, este era composto por oito a dez jovens norte-africanos, quase todos argelinos, de to dos os níve is de en si no, des de a $5^{\text {a }}$ à $8^{\text {a }}$ séries, cuja in ten sa a tivi da de perturba do ra foipossivel verificar (risadas barulhentas, movimentações, empurrões, lan ça men to de co mi da para os cole gas ou para o teto) no de cor rer de vá ri as se ma nas de nos so pri me i ro ano de ob serva ção. De for ma ma ni fes ta, tra ta-se de um agru pa men to de alu nos que com par ti lham o mes mo es ta tu to es co lar e a mes ma pre dis po si ção con tra a ins titu i ção es co lar, cuja li de ran ça era ga ran ti da pelosre pe ten tes maisvelhos. Con tra ria men te aos agru pa men tos for ma dos por alu nos de ori gem asiá ti ca, este gru po foi ob je to, de vi do à sua in dis ci pli na, de uma aten ção par ti cu lar por par te da administração, que acabou por proibir tal ajuntamento na cantina.

Esses ban dos, tão fre qüen tes nos es ta belecimentos escolares nor te-americanos, ou até mesmo britânicos, são bastante excepcionais nes te co lé gio fran cês. Na can ti na, a ma i or par te dos grupos que ocupam as mesas são, a olhos vistos, etnicamente mistos. Além disso, a observa ção re gu lar das ativi da des no pá tio mos tra a exis tên cia de uma ver da de i ra mis tu ra ét ni ca. Os quatro bancos do pátio ficam ocupados, qua se sem pre, por alu nos - na ma i or par te, meni nas - de "co res" di fe ren tes. A ob serva ção dos jogos entre meninos leva à mesmaconclusão: as equi pesquejo gam saké e futebol são sem pre pluriétnicas, do mesmo modo que os pequenos grupos que correm para as mesas de pingue-pongue. ${ }^{16}$ Além dis so, con vém ob servar que a mis tu ra, tan to ét ni ca quan to se xu al, pare ce cres cer com a ida de e o tem po de fre qüên cia no colégio. Na cantina, as mesas mais “coloridas" são aquelas que reúnem o maior nú me ro de alu nos das tur mas de $7^{\text {a }}$ e $8^{a}$ séries. No pá tio de re cre io, quan do o tem po está bom, os alu nos mais ve lhos fi cam jun tos para to mar sol, conversar à toa e praticar diversos jogos em uma pe que na ele va ção de ter re no que dá aces so ao re fe i tó rio e apre sen ta-se como o espaço mais con vi vi al do co lé gio, de tal modo que se mis tu ramaí, fa cil men te, os alu nos de am bos os se xos e de to das as ori gens ét ni cas. Essa aber tu ra ma i or dos alu nos que fre qüentam as úl ti mas sé ri es do co lé gio aos con ta tos interétnicos explica-se por diversos fatores escolares e não-escolares: em particular, a cons ti tuição de umvivido in te rét ni co co mum, no âm bi to da es co la ri za ção em um es ta be le cimen to mul tiét ni co, que se acres cen ta a o vi vido interétnico no bairro, assim como a integração progressiva dos alunos em uma subcultura jovem que adota e reinterpreta elementos oriundos de diferentes tradições culturais (Peshkin, 1991; Lepoutre, 1997; Favre-Perroton, 1999). Mas ela deve ser ana lisada, igualmente, como o resultado de uma au to no mia ma i or dos alu nos que se des lo cam facilmente de uma mesa para outra, de um banco para outro, garantindo assim uma grande fluidez entre os grupos (Zisman e Wilson, 1992).

A ca ma ra da gem en tre alu nos não im pede a exis tên cia de ten sões en tre eles, que fa zem intervir critérios étnicos. Com toda a certeza, convém evitar assimilar, de forma preci pi ta da, a in sul tos ra cis tas as per mu tas de observações, tais como "negro sujo”, "árabe sujo" ou "raça fo di da”. Se tais ex pres sões po dem chocar profundamente os adultos, em particular os professores que são sensíveis particularmente à violência na linguagem, elas assumem um caráter banal entre os

16. A única ocasião em que observamos, com surpresa, o começo de uma partida de basquete entre duas equipes, uma delas composta unicamente por alunos de cor branca, enquanto a outra era formada por alunos manifestamente de origem norte-africana ou negros, um vigilante veio rapidamente nos prevenir que se tratava de uma partida entre os alunos selecionados a dedo da turma de rúgbi de $7^{\mathrm{a}}$ série e outros alunos do colégio; de novo, essa situação mostra como as segregações promovidas na escola podem criar ou reforçar, de mil e uma formas, a segregação étnica. 
alu nos que as uti li zam de ma ne i ra qua se au to mática ou "para fazer gozação", ou seja, segundo uma lógica que tem a ver com a confraternização entre alunos da mesma origem ét ni ca ou de ori gem ét ni ca di fe ren te e, ao mes mo tem po, com o jogo de pa la vras que visa der rubar o es tig ma so ci al li ga do a es ses ter mos (Debarbieux, 1996; Lepoutre, 1997; Favre-Perroton, 1999):

- Você nun ca vê alu nos que se in sul tam ou brigam uns com os outros...

- Exis tem alu nos que se in sul tam, mas isso não é uma ati tu de ra cis ta.

- ...? Então, o que é que eles utilizam como ofensas?

- Bom, eu não sei... "Raça suja”, eu não sei... ou coisasparecidas, é isso.

- É isso que, às vezes, eles uti lizam?

- Sim. Para brincar, também.

(So nia, $6^{\mathrm{a}} \mathrm{D}$ )

- E, no co lé gio "Ver la i ne”, vocêjá ou viu in sultos ra cis tas?

- Não.

- Não? Nem por par te dos pro fes so res, alu nos, ou en tre os alu nos?

- Às ve zes, há quem... eles fa lam, einh... "ne gro sujo", mas des ta for ma não é uma ati tu de ra cista, mas sim ples men te...é as sim.

- Por que mo ti vo eles fa lam "ne gro sujo", em vez de ou tra ofen sa?

- Não sei. Porque isso está na boca de todo mun do. Mas não é todo o mun do que fala isso... so men te al guns alu nos.

(Benja min, ${ }^{\mathrm{a}} \mathrm{F}$ )

No en tan to, qual quer que seja sua ati tude em re la ção aos es tu dos, os alu nos con si deram que é normal que a utilização desses ter mos seja san ci o na da pelos pro fes so res quando tem a ver com o in sul to, ou seja, com a in tenção manifesta de machucar ou humilhar o ou tro, e, até mes mo, às ve zes, quan do são pro fe ri dos "para fa zer go za ção" no es pa ço da sala de aula. Des te modo, eles ma ni fes tam a in te rio ri za ção de uma cer ta dis tin ção en tre o es paço es co lar e o do ba ir ro, as sim como o de se jo dever os pro fes so res de sem pe nha rem um papel de regulação neste campo:

- E se, por exemplo, um professor ouvir um aluno chamar o colega de "negro sujo" ou "ára be sujo" ou "fran cês sujo", e se lhe apli car uma pu ni ção, o que é que você pen sa dis so? - Bom, pen so que está cer to. Se ele pen sa assim, einh... está certo.

- Mes mo se o alu no fa lar isso por brin ca de i ra? - Aí não, se fa lar isso por brin ca de i ra, einh... não. Mas se dis ser isso por pen sar as sim, acho que se ria cer to apli car-lhe uma pu ni ção.

(Sa mi ra, $7^{\mathrm{a}} \mathrm{F}$ )

- Por exem plo, se um alu no cha mar ou tro de "ne gro sujo" e se um pro fes sor se ir ri tar por esse mo ti vo, o que você acha des sa ati tu de? - Bom, em minha opinião, deve aplicar-lhe uma punição, einh... deve aplicar-lhe um ques tio ná rio como pu nição.

- ...? Será que tem razão de aplicar-lhe uma punição?

- Bom, com cer te za, por que não se deve di zer isso. Nós tam bém po de ría mos tra tá-lo de raça fo di da e... por exem plo, se ele for mais for te do que al guém e tudo mais... ele está por cima e lhe disser: "tudo bem, se você responder, bom, eu vou sho o ter você"... é as sim e tudo mais... E o ou tro nada po de rá fa zer... mas não é cer to di zer isso; to dos nós so mos se res humanos.

- ...? E se, por exem plo, um alu no cha mar o colega de "negro sujo", desta vez, simplesmen te por brin ca de i ra, e se o pro fes sor aplicar-lhe uma pu ni ção, o que é que você pen sa dessa atitude?

- Ela não éjus ta; bom, o ou tro aí, o ne gro, talvez lhe diga "tudo bem, era ape nas por brin cadeira" e tudo mais... isso não é grave. Mas exis tem pro fes so res que di zem: "mes mo se for 
por brin ca de i ra, não me im por to; você não de veria di zer uma co i sa des sas na sala de aula".

- Assim mes mo? E o que é que você pen sa a esse respeito?

-... Bom, é tam bém ver da de... Não se deve di zer uma co i sa des sas na sala de aula, é isso. Por que a gen te está es tu dan do, não se deve fa lar, é isso.

- Mes mo se é para fa zer go za ção?

- Bom... eu não sei. Se for por brin ca de i ra, sim, tal vez não te nha de ser pu ni do por mu i to tem po, mas...

- E se não for na sala de aula, mas fora: um pro fes sor está pas san do e ouve um alu no cha mar o co le ga de "ne gro sujo"; se ele apli car uma pu nição ao alu no que in sul tou o ou tro, você pen sa que isso é nor mal?

- Não. Por que se isso es ta va acon te cen do en tre eles, fora do co lé gio, para fa zer go za ção, bom... talvez, fosse por brin ca de ira, para se diver ti rem, e o pro fes sor ou viu e le vou isso a sé rio, é as sim.

(Ahmed, $7^{\mathrm{a}} \mathrm{F}$ )

Além disso, também deve-se sublinhar que nem to das as bri gas têm um con te ú do ét nico, lon ge dis so, e que nos ra ros in ci den tes qua lificados de "racismo entre alunos" por eles próprios, os referentes étnicos interagem, de fato, com ou tros ele men tos da si tu a ção ou da trajetória dos participantes. Com efe ito, os insultos “ét ni cos” dão lu gar, so bre tu do, a bri gas no es ta be le ci men to de en si no ou em suasimedi a ções quan do elas se ins cre vem em uma ló gica de humilhação e de exclusão (comparação explíci ta ou im plíci ta das qua li da desfísi cas ou intelectuais ou desempenhos escolares ou esportivos, os tra cismo, recusa de de ixarumalu no par ti ci par em uma con ver sa ção, em um jogo ou com pe ti ção es por tiva). Além dis so, os con fli tos des se tipo di zem res pe i to, qua se sem pre, a alunos bas tan tejo vens e ré cem-chegados ao es tabelecimento ou mal integrados neste ou na tur ma em ra zão de suas ati tu des e de seu com por ta men to, ou seja, jo vens que não che ga ram a desenvolver uma forte solidariedadecomos colegas.

\section{Conclusão}

Portanto, entre os adolescentes, qual é o pa pel da es co la e, mais pre ci sa men te, da so ciabilidade escolar, na construção da transgressão? A aná li se do dis cur so e das prá ti cas dos alu nos de co lé gio da pe ri fe ria mos tra que alguns assumem no espaço escolar determinadas atitudes e práticas em vigor em seu bairro. Com toda a cer te za, é evi den te que a instituição escolar leva a aceitar, até certo pon to, a exis tên cia de nor mas di fe ren tes das que es tão em vi gor no seio dos gru pos en vol vidos em atividades delinqüentes no bairro, in clu sive da quelas, me nos perigosas, dosbandos de jo vens que pe ram bu lam sim ples men te pela rua. No en tan to, al guns ele men tos mostram que não é evi den te que, para além de um conformismo formal, exista interiorização real dessas normas e, portanto, transposição para além do es pa ço es co lar. Eis o que pa re ce ser, quase sempre, o caso dos jovens de ori gem imi gran te mais di vi di dos en tre a atra ção pela es co la e as so li ci ta ções de um ba ir ro que constituiverdadeiramenteseuterritório e ao qual eles permanecem ligados; ora, às vezes, tal si tu a ção os con duz a uma es pé cie de "vida dupla”, obedecendo a normas diferentes se gundo o contexto de interação.

Se, en tão, pa re ce fá cil lan çar a cul pa ao meio circundante exterior da escola, uma aná li se mais su til do que se pas sa nos co lé gi os da peri fe ria mos tra que exis te no in te ri or destes uma verdadeira apren di za gem da "transgressão”. Por um lado, diante da pressão institucional, do enfado e sentimen to de injustiçasuscitados pelas avaliaçõesnegativas, pelo en ca mi nha men to a tur mas for ma das por alu nos com fra co de sem pe nho es co lar, as sim como pelas orien tações edu ca cio na is direcionadas para os ramos de escolarizaçãomenos valorizados, os alunos que, na escola primária, aderiam for te men te aosvalo res es cola res e respeitavam a autoridade dos professores (Rayou, 1998), to mam, aos pou cos, dis tân cia 
em relação às normas da instituição (Dubet e Martucelli, 1996). ${ }^{17}$ Por ou tro lado, nes sas tur mas, a exis tên cia de uma de sor dem anô mi ca recorrente que, por impotência dos professores, não che ga a ser con tro la da, leva os ado les centes a so ço brar em um es ta do de "de ri va". Esse es ta do deirresponsabilida de edeim po tên cia é, talvez, ain da mais per ni ci o so do que a re sis tência opo si to ra des cri ta por Wil lis (1977), na medida em que conduz ao desenvolvimento de uma orientação fatalista que diz respeito não só aos estudos, mas à vida em geral; por sua vez, pode levar uma fração dos alunos a "en grenarem" em atividades verdadeiramente de linqüentes(Broccolichi e Oeuvrard, 1993).

Com toda a certe za, nes sas tur mas, existem alunos que adotam comportamentos "pró-escola" e ou tros que se ins cre vem, so bre tu do, em uma ló gi ca “an ti es co la”. Os primeiros têm um nú me ro ma i or de in te ra ções com os cole gas da tur ma, na sala de aula, no co lé gio e, de for ma mais li mi ta da, no ba ir ro, o que os aju da a perma necerem mobiliza dospeloses tudose ativi da des es co la res. Osse gun dos têm um nú me ro ma i or de in te ra ções com alu nos que não fa zem parte da turma, tam pou co do es ta bele cimen to. Ora, mu i tas ve zes, es sas ami za des e suas re des ex te ri o res à tur ma le vam os alu nos a se afas ta rem, aos pou cos, da pro gra ma ção es co lar e a se mobiliza rem por ou tras ativi da des. No en tan to, a distinção entre "pró-escola" e "antiescola", cara a os pes qui sa do res bri tâ ni cos, revela-se, no conjun to, cada vez me nos per ti nen te à me di da que os alunos avançam na escolaridade no colégio e, mais parti cularmen te, se gun do pa rece, no caso dos adolescentes oriundos da imigração. Por um lado, como é ve ri fi ca do pe los es tu dos que in ci dem so bre osjo vens das minorias étnicas nos Estados Unidos ou na Grã-Bretanha, uma gran de par te des ses ado lescentes parece, ao mesmo tempo, mobilizada pelos estudos e oposta às normas escolares, mas sob uma for ma - no iní cio, de pre fe rên cia, moderada - que pode ria permitirain te gra ção si mul tâ nea na es co la e no gru po dos pa res. No en tan to, por ou tro lado, em ra zão da in ca paci da de dos adul tos para con tro la rem as si tuações de ensino nas "turmas fracas", a opo si ção-brincadeira des ses alu nos vira fa cilmen te ver da de i ra de sor dem, sen do que as dinâmicas propriamente "antiescola” acabam, então, por levar a melhor.

0 fato de co lo car a ên fa se no pa pel da se gre ga ção es colare das prá ti caspe da gó gi cas na constituição da trans gres são não devele var a mi ni mi zar o pa pel das re des de ami za de e de sociabilidade. Muitas vezes, estas têm uma base étnica, mas nem por isso pode-se de duziruma ori en ta ção es pe cífica das con dutas em função da composição de tais redes: algumas redes étnicas são francamente "pró-escola", outras francamente "antiescola”, e ain da ou tras - tal como o gru po de me ni nos da tur ma de $7^{\text {a }}$ sé rie es tu da da por nós po dem ser ora uma co i sa, ora ou tra. Portan to, não se pode con clu ir, como é fe i to de for ma precipitada por alguns professores, que bastaria destruir os "grupinhos influentes" formados por alunos de origem estrangeira para impedir a emergência de práticasdesviantes. Em compensação, o que parece ser evidente é que a ativi da de re pres so ra di re ci ona da para as re des des vi an tes, es tejam ou não organizadas na base étnica, aumenta quase sem pre sua vi si bi li da de e a re pu ta ção de " durões" atri bu i da a seus mem bros, o que, como é demonstrado por outros estudos, leva ao isolamento ain da ma i or des ses alu nos em relação ao resto da comunidade escolar, assim como ao reforço do peso das atitudes e das práticas antiescolares (Wright, 1987; Connolly, 1995). Além disso, importa observar

17. As pesquisas em grande escala empreendidas sobre esta questão mostram, por exemplo, que a proporção de alunos que pensam que "é aceitável não comparecer a um curso enfadonho" passa de $10 \%$, na $5^{\text {a }}$ série, para $40 \%$ na $8^{\text {a }}$; a proporção dos alunos que acham "aceitável copiar de um vizinho a resposta a um exercício difícil" passa de $10 \%$ para mais de $50 \%$; e a proporção daqueles que pensam que é "aceitável mentir para evitar uma punição" passa de menos de 30\% para quase $70 \%$ (Grisay, 1997). 
que "trans gres são" e "ra cis mo en tre alu nos" raramente vão de par, contrariamente ao que constatava Willis (1977) na Inglaterra. Com efeito, com a melhoria das relações entre alu nos à me di da que es tes avan çam em sua es co la ri da de no co lé gio (Paty, 1980), ve ri fi ca-se, nos contextos multiétnicos, uma abertura mais acentuada dos gru pos em di re ção dos co le gas de origens diversas; ora, segundo parece, as me ni nas con tribu em para tal aber tu ra, uma vez que os gru pos se xu al men te mis tos são tam bém os mais aber tos no pla no ét ni co (Her pin, 1996).

Mas, justamente, se o peso dos grupos in for ma is pa re ce ser cen tral no caso dos me ninos - aliás, até aqui, o tópico mais explorado por nós -, tal fe nô me no re ve la-se, sem dú vi da, me nos de ci sivo no caso das me ni nas, por diversas razões. Em primeiro lugar - e, principalmente, em relação às jovens oriundas da imigração norte-africana -, elas estão menos divididas, de saída, entre o bairro e a escola porque não têm, propriamente falando, uma vida de ba ir ro. Com toda a cer te za, pode exis tir uma opo si ção en tre a cul tu ra fa mi li ar e a da es co la, mas tal opo si ção é mais sur da e in dividu al. Em se gun do lu gar, elas têm uma so ci a bilidade mais intimista, dentro ou fora da turma, que serve com menos freqüência de pon to de apo io a for mas de opo si ção co le tiva. Por último, como é demonstrado por várias pes qui sas, pa re ce que elas são mais ca pa zes de con ci li ar uma ati tu de pró-escola com prá ti cas desvian tes que são me nosiden ti fi cáve is ou, em todo caso, me nos san ci o na das pe los pro fes sores(Fuller, 1980; Peignard et al ., 1998). No entanto, se as meninas provenientes do meio popular e, em particular, aquelas ori un das da imigração se dão glo bal men te me lhor no que diz res pe i to à es co la ri da de no co lé gio, elas so frem tan to quan to os co le gas com o cli ma que re ina nas tur mas for ma das por alu nos com fraco de sem pe nho es co lar; além dis so, a tal cli ma acres cen ta-se a re je i ção de que são ob je to por par te dos me ni nos que, do pon to de vis ta numé ri co e so cial, ocu pam aí uma po si ção do minante (Raissiguier, 1994).

\section{Referências bibliográficas}

BALL, S. Beachsidecomprehensive: a case study of com pre hen si ve scho o ling. Cam brid ge: Cam brid ge Uni ver sity Press, 1981.

BALL, S.; van ZANTEN, A. Logiques de marché et éthiques contextualisées dans les systèmes scolaires fran ça is et britannique. ÉducationetSociétés, n.1, p.47-71, 1998.

BALLION, R. Les dif fi cul tés des lycées vues à tra vers les trans gres si ons. In: CHARLOT, B.; EMIN, J. C. (Ed.) Violencesà l'école: état des sa vo irs. Pa ris: A. Co lin, 1997. p.41-59.

BARRÈRE, A. Les lycéens au tra va il. Pa ris: PUF, 1997.

BORDET, J. Les je u nes de la cité. Pa ris: PUF, 1998.

BRAKE, M. Comparativeyouth culture: the so ci o logy of youth sub cul tu res in Ame ri ca, Bri ta in and Ca na da. Lon dres: Rou tled ge \& Ke gan Paul, 1985.

BROCCOLICHI, S.; OEUVRARD, F. L'engrenage. In: BOURDIEU, P. (Org.) La misè re du mon de. Pa ris: Éd. du Se u il, 1993. p.639-648.

BROCCOLICHI, S.; van ZANTEN, A. Espa ces de con cur ren ce et cir cu its de sco la ri sa ti on: l'évitement des coll èges pu blics d'un dis trictde la ban lie ue parisienne. Les Anna les de la Re cherche Urbaine, v.75, p.5-31, 1997.

CARRA, C.; SICOT, F. Une au tre pers pective sur lesvio lencessco la ires: l'expérience dev ic timation. In: CHARLOT, B.; EMIN, J. C. (Ed.). Violencesàl'école: état des sa vo irs. Pa ris: A. Co lin, 1997. p.61-82. 
CHARLOT, B.; BAUTIER, E.; ROCHEX, J. Y. École etsavoirdansles banlie ues etaille urs. Pa ris: A. Co lin, 1992.

CHARLOT, B.; EMIN, J. C. (Ed.) Violencesàl'école: état des sa vo irs. Pa ris: A. Co lin, 1997.

COHEN, A. Delinquentboys: the cul tu re of the gang. Glen coe: Free Press, 1955.

COLLINS, P. From cour tro oms to class ro oms: managing scho ol de se gre ga ti on in a deep sout h high scho ol. In: RIST, R. (Ed.) Desegregateschools: ap pra i sals of an ame ri can ex pe ri ment. Nova York: Aca de mic Press, 1979. p.89-114.

CONNOLLY,P. Racism, mas culin pe er-group re lations and the scho o ling of African/Ca rib bean infantboys. British Journal of Sociology of Education, Shef fi eld, v.16, n.1, p.75-93, 1995.

DEBARBIEUX, E. Laviolenceenmilieuscolaire. État des li e ux. Pa ris: ESF, 1996. v.1.

DEBARBIEUX, E.; GARNIER, A.; MONTOY, Y.; TICHIT, L. Laviolenceenmilieuscolaire: le dé sor dre des cho ses. Paris: ESF, 1999. v.2.

DUBET, F.; MARTUCELLI, D. À l'école: sociologie del'expériencescolaire. Pa ris: Éd. du Se u il, 1996.

DURET, P. Anthro po logie de la fra ter nitédans les cités. Pa ris: PUF, 1996.

DURU-BELLAT, M.; MINGAT, A. La ges ti on de l'hétérogénéité des pu blics d'élèves au coll ège. Les Ca hi ers de l'IREDU, Di jon, v.59, 1997.

FAVRE-PERROTON, J. École etethnicité: une re la ti on à dou ble face. Bor de aux, 1999. Tese (dou to ra do). Univer si da de de Bordeaux2.

FOLEY, D. Learning capitalistculture: deep in the he art of Te jas. Phi la delp hia: Uni ver sity of Pennsylva nia Press, 1990.

FORDHAM, S.; OGBU, J. Black stu dents' scho ol suc cess: co ping with the bur den of ac ting whi te. The Urban Re view, v.18, p.176-206, 1986.

FULLER, M. Black girls in a Lon don com pre hen si ve scho ol. In: DEEM, R. (Ed.) Scho o ling for wo men's work. Lon dres: Rou tled ge \& Ke gan Paul, 1980.

GRISAY, A. L'évolution des ac quis cog ni tifs et so cio-affectifs des élè ves au cours des an nées de coll ège. LesDossiers d'Éducation etFormation, v.88, 1997.

HALLINAN, M.; SMITH, S. The effets of class ro om racial com po sition on stu dents inter racialfriendliness. SocialPsychology Quarterly, v.48, n.1, p.3-16, 1985.

HALLINAN, M.; WILLIAMS, R. Interracial friendship choices in secondary schools. American Sociological Review, Was hing ton, v.54, p.67-78, 1989.

HAMMERSLEY, M.; TURNER, G. Con for mist pu pils? In: WOODS, P. Pupilstrategies : ex plo ra ti ons in the so ci o logy of the scho ol. Lon dres: Cro om Helm, 1980.

HAMMERSLEY, M.; WOODS, P. The pro cess of scho o ling. Lon dres: Rou tled ge \& Ke gan Paul, 1976.

HARGREAVES, D. Socialrelationsina secundary school. Lon dres: Rou tled ge \& Ke gan Paul, 1967.

HARGREAVES, D.; HESTER, S.; MELLOR, F. Devianceinclassrooms. Lon dres: Rou tled ge \& Ke gan Paul, 1975.

HENRIOT-van ZANTEN, A. L'école et l'espace lo cal: les en je ux des zo nes d'éducation pri o ri ta i res. Lyon: PUL, 1990.

HERPIN, N. Les amis de clas se: du coll ège au lycée. ÉconomieetStatistique, n.293, p.125-136, 1996.

HOGGART, R. 33 Newport Street: autobiographie d'un intellectuel issu des classes populaires anglaises. Paris: Gallimard/LeSeuil, 1991. 
LACEY, C. Hightown grammar. Man ches ter: Man ches ter Uni ver sity Press, 1970.

LAGRANGE, H. Les ado les cents, le sexe, l'amour. Pa ris: Syros, 1999.

LEPOUTRE, D. Coeurdebanlieue: co des, rites etlangages. Pa ris: Odi le Ja cob, 1997.

MATZA, D. De linquencyand drift. Nova York: John Wi ley \& Sons, 1964.

McLEOD, J. Ain't no ma king it: le ve led as pi rati ons in a low in co me ne igh bor ho od. Boul der, C0: West vi ew, 1987.

METZ, M. Sources of construc tive social re lations hips in an urban mag netscho ol. American JournalofEducation, Chicago, p.202-245, feb. 1983.

OGBU, J. Thenextgeneration: an eth no graphy of edu cation in an urban ne igh borho od. Nova York: Aca de mic Press, 1974.

Cultural boun da ri es and mi no rity youth ori en ta ti on to ward work pre pa ra ti on. In: STERN, D.; EICH HORN, D. Ado lescence and work. Hill sda le: Law ren ce Eri ba um, 1989. p.101-140.

PATY, D. Douze collèges en France. 2.ed. Paris: La Do cumentation françai se, 1996.

PAYET, J. P. Collègesdebanlie ue: eth nograp hie d'un mon de scolaire. 2. ed. Paris: Méri di ens Klincksi eck, 1997.

PAYET, J. P.; van ZANTEN, A. L'école, les en fants de l'immigration et des mi no ri tés eth ni ques: une re vue de la litté ra tu re française, américaineetbritannique. RevueFrançaisedePédagogie, Paris, v.117, p.87-149, 1996.

PEIGNARD, E.; ROUSSIER-FUSCO, E.; van ZANTEN, A. La violence dans les établissements scolaires britanniques: approchessociologiques. RevueFrançaisedePédagogie, Pa ris, v.123, p.123-151, 1998.

PESHKIN, A. The co lor of stran gers, the co lor of fri ends: the play of eth ni city in scho ol and com mu nity . Chi ca go: The Uni ver sity of Chi ca go Press, 1991.

POLLARD, A. The so ci al world of the pri mary scho ol. Lon dres: Holt, Ri ne hart and Wins ton, 1985.

RAISSIGUIER, C. Becoming wo men, be coming workers: iden tity for ma ti on in a french vo ca ti o nal scho ol. Albany: SUNY, 1994.

RAYOU, P. Lagran de éco le: ap prochesociologiquedescom pétencesenfantines. Paris: PUF, 1999.

REYNOLDS, D. When pu pils and te a chers re fu se a tru ce: the se con dary scho ol and the cre a ti on of de lin quency. In: MUNGHAM, G.; PEARSON, G. (Ed.) Working class youth cul tu re. Lon dres: Rou tled ge \& Ke gan Paul, 1976.

RIST, R. (Ed.) Desegregateschools: ap praisals of anamerican expe riment . Nova York: Aca de mic Press, 1979.

ROCHEX, J. Y. Le sens de l'expérience scola ire. Pa ris: PUF, 1995.

SCHERER, J.; SLAWSKI, E. Co lor, class and so ci al con trol in an ur ban de se gre ga ted scho ol. In: RIST, R. Desegregate schools : ap pra i sals of an ame ri can ex pe ri ment. Nova York: Aca de mic Press, 1979. p.117-154.

STERN, D.; EICHHORN, D. (Ed.) Adolescence andwork. Hill sda le, N.J.: Lawrence Eriba um, 1989.

TESTANIÈRE, J. Chahut traditionnel et chahut anomique dans l'enseignement du second degré. Revue Françaisede Sociologie, Pa ris, v.8, p.17-33, 1967.

TROYNA, B. (Ed.) Racialine quality in education. Londres: Ta vistock, 1987.

WHYTE, W. F. Streetcornersociety: the so cial struc tu re of an italian slum. Chicago: The Univer sity Chicago Press, 1943.

WILLIS, P. Learning tola bor: how wor king class lads get wor king class jobs. Farn bo rough: Sa xon Hou se, 1977. 
WILLMOTT, P. Ado les centboys of East Lon don. Lon dres: Rou tled ge \& Ke gan Paul, 1966.

WOODS, P. Ha ving a la ugh: an an ti do te to scho o ling. In: HAM MERSLEY, M.; WO ODS, P. The process ofschooling. Londres: Rou tled ge \& Ke gan Paul, 1976.

WOODS, P. (Ed.) Pupilstrategies: explo rations in the sociology of the scho ol. Lon dres: Cro om Helm, 1980.

W00DS, P. The hap piestdays? How pu pils cope with scho ols . Le wes: Fal mer Press, 1991.

WRIGHT, C. Blackstu dents-white te a chers. In: TROYNA, B. Racialinequalituineducation. Lon dres: Ta vis tock, 1987.

YOUNG, M.; WILLMOTT, P. Fa mily and kins hip in East Lon don. Lon dres: Rou tled ge \& Ke gan Paul, 1957.

ZANTEN, A. Fa brica ti on et ef fets de la sé gré ga ti on sco la ire. In: PAUGAM, A. (Ed.) L'exclusion: état des sa vo irs. Pa ris: La Découverte, 1996.

Scho o ling im mi grants in Fran ce in the 1990s: suc cess or fa i lu re of the Re pu bli can model of in te gration? AnthropologyandEducation Quarterly, v.28, n.3, p.351-374, 1997. 2001. L'écolepériphérique: fabrication eteffets de la ségrégationscolaire.Paris: PressesUniver sitaires de France,

ZIROTTI, J. P. Le ju ge ment pro fes so ral: un système de clas se ment "qui ne faitpas de différence". LangageetSociété, v.14, p.3-42, 1980

ZISMAN, P.; WILSON, V. Ta ble hop ping in the ca fe te ria: an ex plo ra ti on of 'ra ci al in te gra ti on' in early ado les cent so cial groups. AnthropologyandEducation Quarterly , v.23, p.199-219, 1992.

Agnès van Zan ten é so ció lo ga da edu ca ção e pes qui sa do ra do CNRS (Cen tre Na ti o nal de la Re cher che Scientifique), na Fran ça. Trabalhano Observato ireSociologiqueduChenge ment. Entresuas publicações es tão os li vros Sociologiedel'école (com M. Du ru-Bellat, Pa ris: A Col lin, 1992, 1999) e, como or ga ni za do ra, ao lado de A. Pa ugam, L'école: l'état des sa vo irs (Paris: LaDecouvérte, 2000). 